\title{
The Effect of COVID-19 on Academic Social Life in Riyadh with a Focus on the Outdoor Environment
}

\author{
Hind Abdelmoneim Khogali ${ }^{1}$ \\ ${ }^{1}$ College of Architecture Engineering and Digital Design, Dar Al Uloom University, Riyadh City, Saudi Arabia \\ Correspondence: Hind Abdelmoneim Khogali, College of Architecture Engineering and Digital Design, Dar Al \\ Uloom University, Riyadh City, Saudi Arabia. ORCID ID: https://orcid.org/0000-0002-0738-4583
}

Received: February 15, 2021

Accepted: May 26, 2021

Online Published: May 27, 2021

doi:10.5539/mas.v15n3p45

URL: https://doi.org/10.5539/mas.v15n3p45

\begin{abstract}
On 18 March 2020, the World Health Organization announced that the coronavirus disease 2019 (COVID-19) pandemic had reached global pandemic status. The Ministry of Health in Saudi Arabia implemented a COVID-19 lockdown that lasted for four months. After the period of restrictions ended, people were supposed to return to their normal social lives; however, the lockdown had a psychological impact on people without them being aware of it. This research aimed to study the effect of COVID-19 on social life, mainly focusing on six public activities: visiting shopping malls, mosques, open spaces, interior space, psychological effect, and occupational aspects. The Method survey was distributed during lockdown including the six focus areas and collected using Google Forms. Also, a computer program simulation (ENVI-MET) was used to study and develop an outdoor environment. The research focuses on the outdoor environment to find solutions on a sample used Al Rouda Park in Riyadh. The results demonstrated that people are slowly returning to their social lives during the COVID-19 pandemic by steadily visiting shopping malls, mosques, and open spaces and half of respondents stay at home fearing COVID-19. The research concluded that people should apply health procedures during ongoing time in studied locations and should manage the elaborated psychological effects.
\end{abstract}

Keywords: COVID-19, sustainability, social life, psychological impacts, occupational aspects

\section{Introduction}

Although the coronavirus disease 2019 (COVID-19) lockdown ended in June 2020, people remained at home. A small percentage of people are, however, slowly resuming their social lives. This makes studying the impact of COVID-19 on social life crucial, especially for the three main activities in Saudi Arabia: shopping at malls, praying at mosques, and visiting open spaces. Therefore, accommodations must be made (e.g., shaping the design of interiors and outdoor environments), and studying the psychological effects and occupational aspect is required.

The literature reviewed regarding the six focus areas; Echegaray, produced a report that discussed many topics, for example, the post-COVID-19 world, implementing sustainable lifestyles, work, workplaces, family, love, social life, well-being, personal health, education, training, leisure, entertainment, consumption, mobility, housing, living spaces, citizenship, interactions with the state, financial security, social equality, health care provision, and medical reassurances. Among these areas, we focused on the effect of COVID-19 on social life after the end of the lockdown, especially regarding designing interior and exterior spaces, for example, shopping malls and mosques, and its psychological effects on people (Echegaray, F., 2020). Abid, discussed COVID-19 in daily life and stated that it affects social distancing with peers and family; decreases national and international travel; disrupts the celebrations of cultural, religious, and festive events; causes undue stress among the population; results in the closure of hotels, restaurants, and religious places; poor cash flow in the market (Abid Haleem, R. V., 2020). Jiang stated that social distancing involved maintaining $1.5 \mathrm{~m}$ between individuals, which can prevent the spread of most respiratory infectious diseases (Jiang1, Meirui, 2020). People can return to their lives by maintaining this distance and can reduce the spread of severe acute respiratory syndrome coronavirus 2 (SARS-CoV-2) by wearing masks and washing hands. The aim of this study is to contextually identify and assess the consequences of SARS-Covid-19 on social life in Riyadh City by the distributed survey to academics in three universities and record their response in designing the interior space, designing the outdoor space, praying in mosques, visiting shopping malls and its psychological effect on people. 


\section{Literature Review}

\subsection{Definition of Social Life}

Webster stated that Social life is defined as the part of an individual's time that is spent doing enjoyable things with others, as investigated by (Webster, M., 2020) Minor stated that Life as a notion that is difficult to define has also been investigated social life is about the existence and the activity of an organic being or the ability to be born, develop, reproduce, and die. The social is what is linked to society: a community of individuals that share a common culture or interest (Minor, M. T., 2018).

The following are the tentative parameters that impact health:

- The impact of designs on interior spaces.

- Redesigning public spaces.

- The impact on praying in the mosque.

- The impact on visiting shopping malls.

- The impact on psychological well-being.

- Occupation aspects

We focused on the effects of COVID-19 in five areas, namely, interior, and exterior spaces, mosques, and shopping malls, and the impact on psychological well-being, because COVID-19 has affected these parameters.

\subsection{Impact on the Design of Interior Spaces}

In this regard, Solution discussed the future trends in housing interior design and the associated factors, including building systems, air ventilation, and filtration, relative humidity, and temperature. Figure 1 shows social distancing in interior spaces (Solution, E. D., 2020). Sameh focused on creating resilient cities in Jeddah after the COVID-19 pandemic (Sameh, S., 2020). They discussed a webinar regarding the new implementation of green buildings in Saudi Arabia. Riyadh. The capital and financial center of Saudi Arabia was also investigated regarding the challenges facing green buildings; the recommendation was that the focus during the COVID-19 pandemic should be on human health (Al-Serf, M., 2020) Al-Serf discussed how to implement the Internet of things to support sustainability in the Mena region, focusing on smart solutions in green buildings (Al-Serf, M., 2020). Figure 1 shows social distancing in interior spaces.
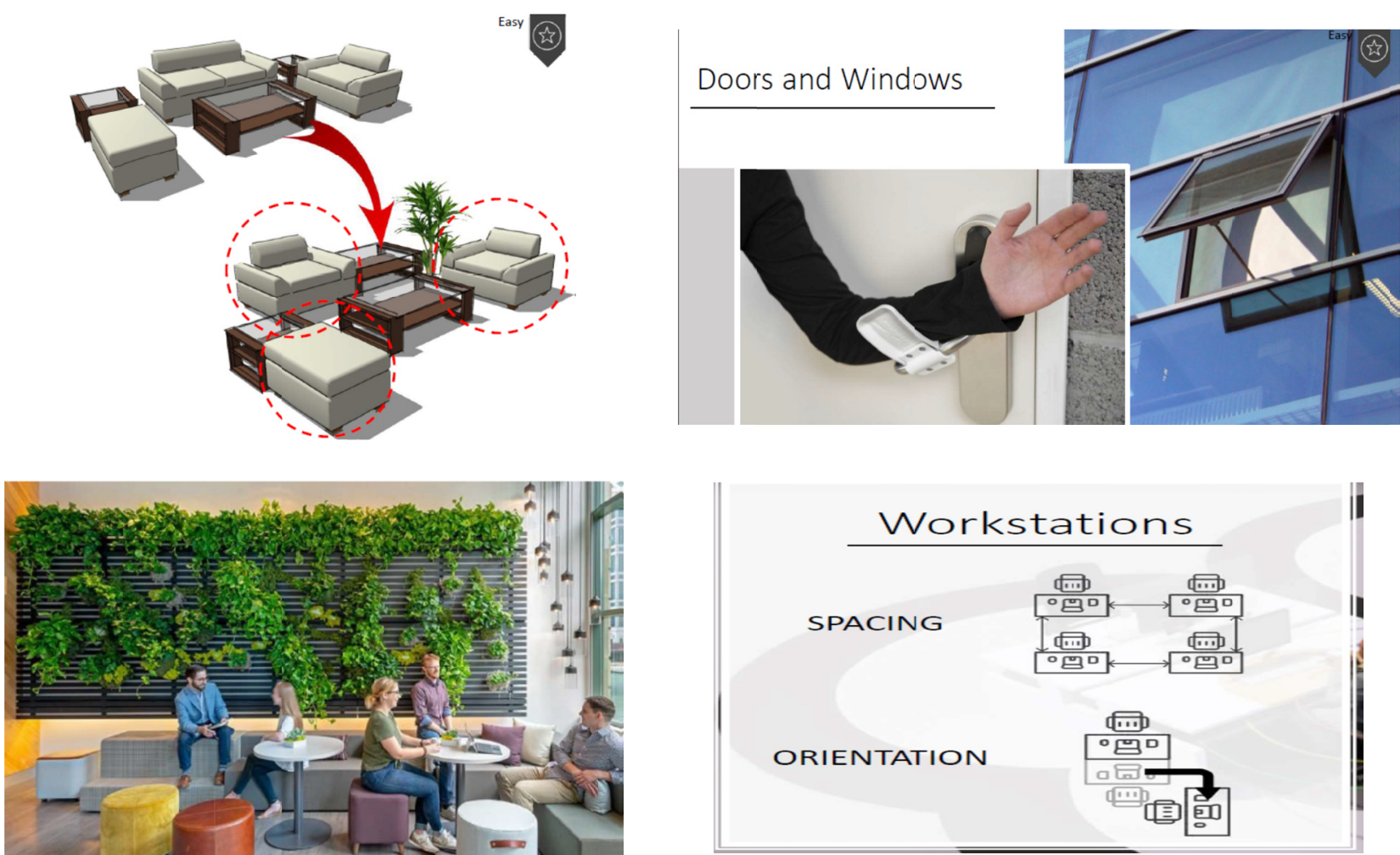

Figure 1. Social distancing in interior spaces 


\subsection{Redesigning Public Spaces}

In this context, Scott reported the risks of COVID-19 in the long term and stated that, if left unchecked, there would be a risk that inequalities and social deprivation will increase. However, these risks provide an opportunity to build a better world that should be realized. Scott agreed that the interior and exterior landscapes must be reshaped to ameliorate the risks of COVID-19. Figure 2 shows the different solutions applied in outdoor spaces (Scott, J., May 2020).

Cortesãoa discussed the sustainability and thermal comfort of public spaces and stated that designers should study thermal comfort in outdoor spaces by studying wind directions, solar angles that provide benefits from trees, and the designs of spaces to provide comfort (Corvacho, H., 2020 Jalal studied the impact of evolving building morphologies on thermal comfort in public spaces in hot, arid climates, and stated that trees and sitting areas with social distancing should be provided (Jalal, O. M., 2020). Jiang also discussed social distancing (Jiang, 2020). Sameh provided a webinar on the influence of COVID-19 and quarantine on lifestyle and home design (Sameh, S., 2020). Besides, Echegaray stated that the world is anticipating post-COVID-19 life and the implications for sustainable lifestyles from a Global South perspective (Echegaray, F., 2020) Figure 2 shows solutions applied in outdoor spaces discussed in webinar by Jalal.
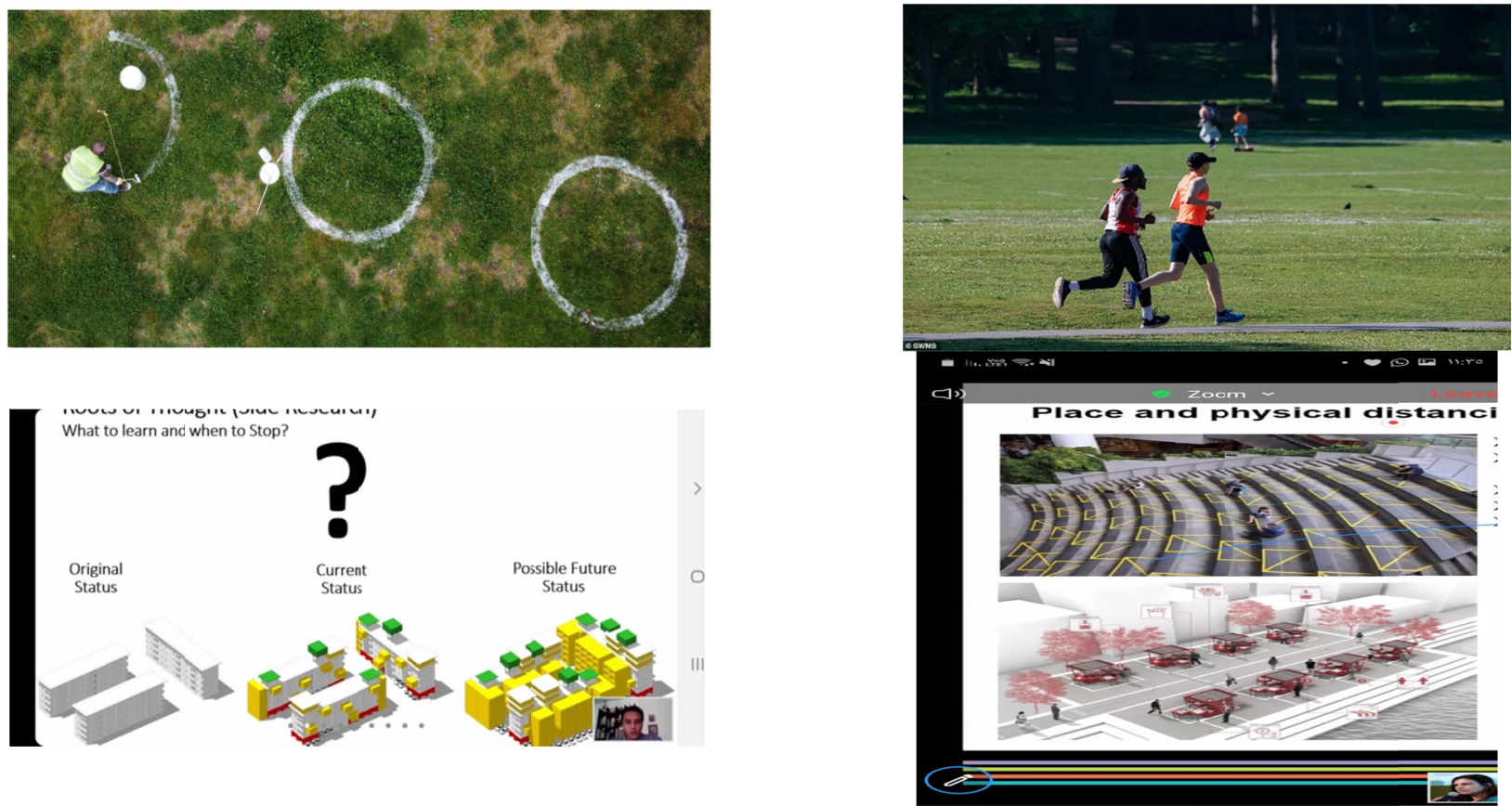

Figure 2. Solutions applied in outdoor spaces. Source: Jalal (Jalal, O. M., 2020)

\subsection{Impact on Designing Mosques}

During the COVID-19 pandemic (from Feb.2020 to May 2020), people have rarely visited mosques: some people visit the mosques once a week, others twice, and most of them are not visiting at all. Health procedures were applied in all mosques. Moreover, (Authority, P. H., 2021) and (Health, M., 2021), published the protocols of the Ministry of Health and procedures used inside the mosques, including:

- Hygiene, physical distancing, and working remotely.

- Toilets: applying social distancing and supplying liquid soap.

- Permitting open toilets and ablution places in mosques, provided that a worker is designated to disinfect them after each obligatory prayer.

- Symptom monitoring and reporting.

- Increasing COVID-19 awareness in mosques.

- More cautions were added by the government in Riyadh regarding praying in the mosques during Ramadan 2021, such as regular cleaning, bringing your own prayer carpet. Apply Tawakkalna software. 

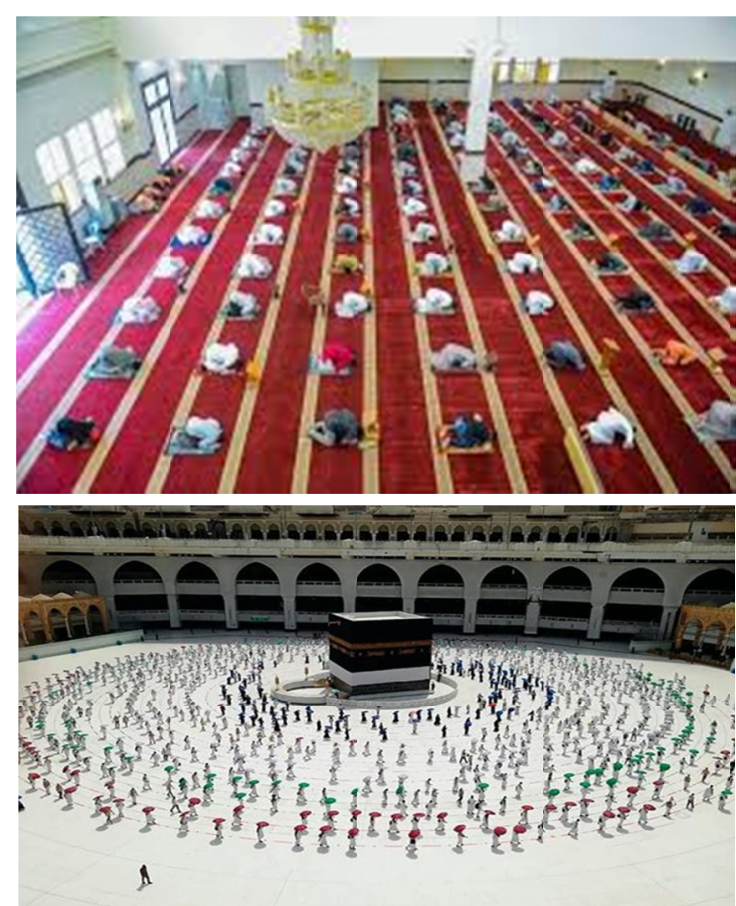
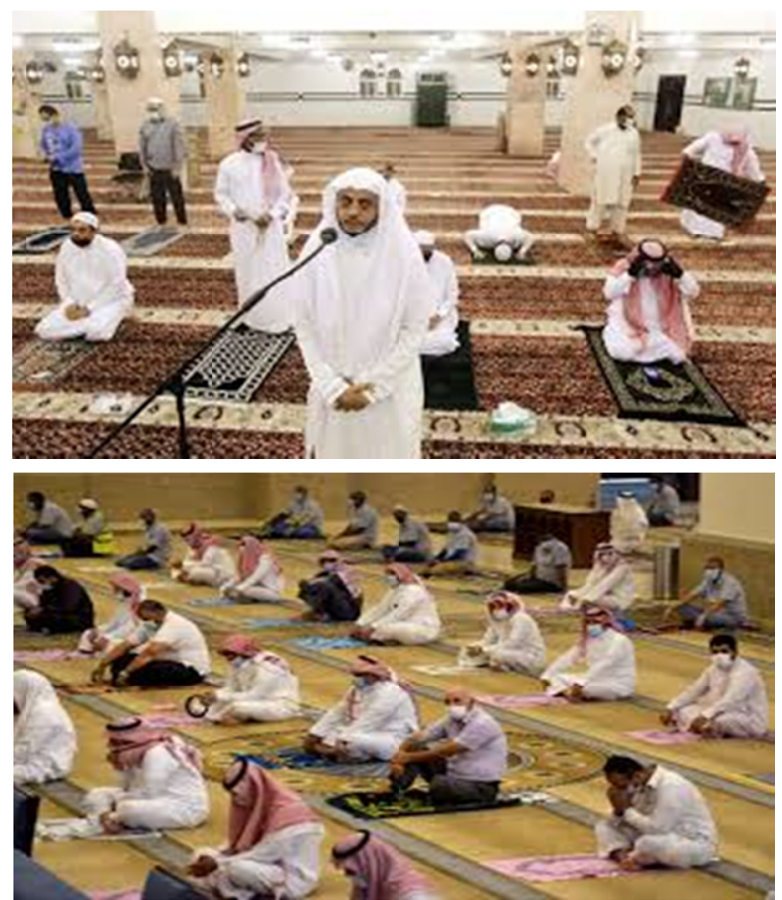

Figure 3. Mosque designs. Source: (News, A., 2021)

\subsection{Impact on the Operation of Shopping Malls}

People have slowly started to visit shopping malls, which are also applying social distancing and health procedures. News discussed the health procedures in shopping malls (News, A., 2021). Including:

- $\quad$ Shoppers must undergo temperature checks at the entrance to stores.

- They are required to keep two meters away from each other and wear face masks and gloves.

- Children under the age of 15 years are not allowed entry.

- Entertainment venues, cafes, and restaurants in shopping centers are to remain closed according to COVID-19 regulations.

- Applying the smart application to reduce to measure the number of people inside the shopping mall to be within 50 persons/hours.

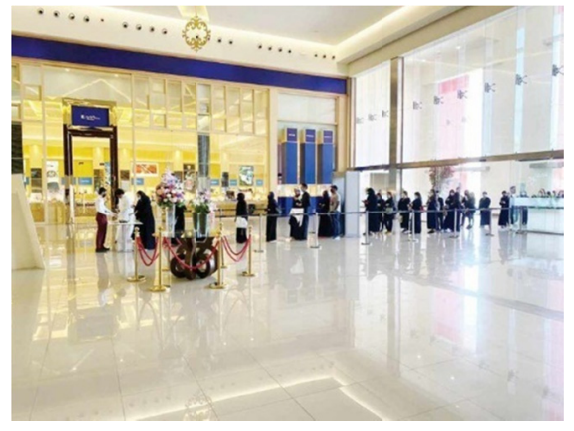

(a)
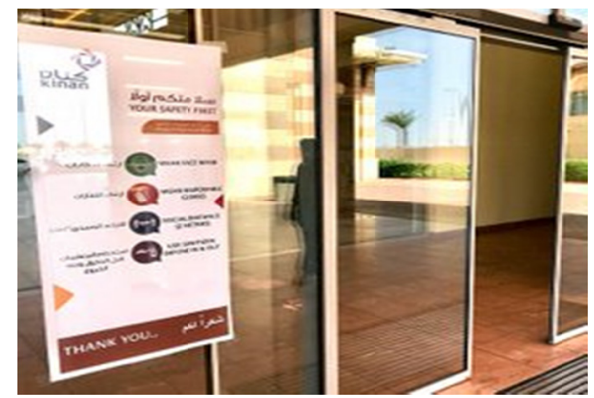

(b) 


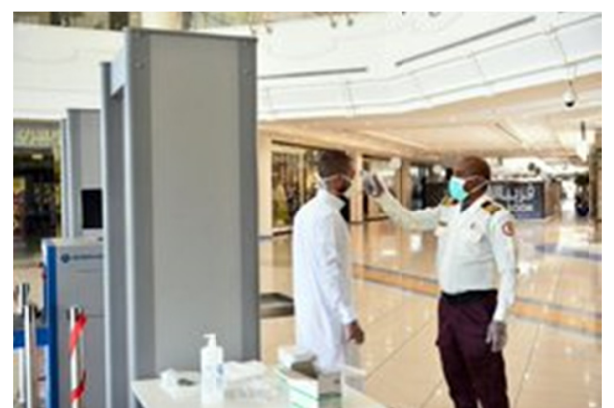

(c)

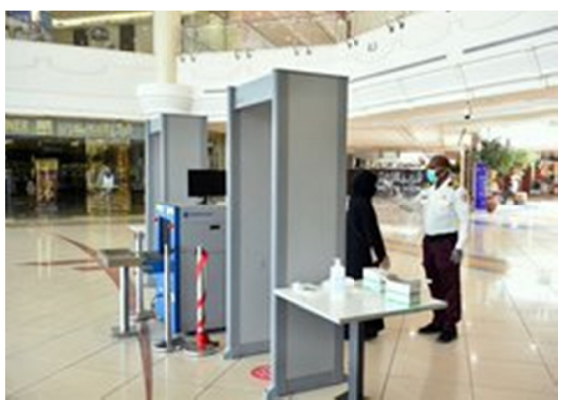

(d)

Figure 4. Impact of COVID-19 on shopping malls. Source: (News, A., 2021)

\subsection{Psychological Impacts}

On 18 March 2020, the World Health Organization issued a report related to the mental health and psychosocial concerns due to COVID-19 and provided instructions and social considerations to apply during the COVID-19 outbreak. Blue Nile TV presented interviews with famous program presenters affected by COVID-19 and asked them about the psychological impact of COVID-19 and how they recommend overcoming the disease; They said that the symptoms were a headache, coughing, fatigue, a sore throat, and a loss of taste or smell (Blue -Nile., 2020).

Prevention stated that the psychological effects started with individuals refusing to admit that they had COVID-19 when the fever started. Subsequently, they took the test and received a positive result. At this time, they began admitting that they had the disease and visited a specialized therapist. There was no specific treatment. The recommended medical advice was to take antibiotics and pain relief and to isolate themselves from their family and the community; this protocol resulted in deep psychological impacts (Prevention, C. O., 2020).

Also, the WHO reported an increasing number of incidences of domestic violence, divorce, and suicide (WHO, 2020).

\subsection{Occupational Aspects}

Neeraj stated that COVID-19 has deep occupation effect on the Academics. Mishar stated that COVID-19 has affected our life, our daily routine, lifestyle, office wok and the future plan was interrupted, with focus on occupation it affected how people access and undertake with COVID-19 pandemic, access resources, mobility, social isolation, issues with mental health and well being (Neeraj, M., 2020). Also, Lachan discussed the impact of COVID-19 on the teaching workforce, a new focus on remote learning, new protocolls in health and safety, distance learning, working conditions, unemployment in other sectors (Lachlan, L., 2020). In addion Jain highlighted the important of training programs to the teachers to fill the gap in accessibility, usage, and e-teaching and learning skills (Jain, S., 2021). Khogali discussed her university conditions having its own experience regarding the occupational aspect stated that teaching in Saudi Arabia was changed to e-learning as a special case during April to May 2020 and changed to blending learning from Sep 2020 to April 2021, and so were the practical courses on campus, and the theoretical courses online (Khogali, H., 2020).

\subsection{The Latest Researches in the Field of the Study}

Kukenkov discussed the organization of interior spaces using new approaches regarding the assimilation of researched objects, considering color-tonal modeling, and expanding the scope of the organization of space-associated and structural elements (Kukenkov, V., 2020). Gruenwald stated that COVID-19 affected outdoor advertisements in the form of signs and billboards, reporting that we can use QR codes and code names specific to a campaign, along with hashtags on social media like Instagram, Facebook, and Twitter as solutions to this problem (Gruenwald, H., 2021). Freeman discussed COVID-19 and outdoor safety in- depth and highlighted some solutions, such as reducing the number of people entering the public park, staying 2 meters away from others, limiting the access to activities, managing the outdoor space, and introducing mental health agencies to deal with COVID-19-related stress (Freeman, Sh., 2020). Clouston, in this study, suggested how the outdoor transmission of COVID-19 may occur by noting that the risk of transmission of COVID-19 in the summer was highest on days when the wind was reduced (Clouston, S. A., 2021). Lannoy discussed the importance of outdoor space for children and youth, with outdoor play being important for children's physical and mental health; therefore, provincial policies related to COVID-19 and outdoor play are needed (Lannoy, L. d., 2020). 
Xie analyzed the importance of outdoor space and stated that that urban parks and large outdoor open spaces can provide residents with a place for safe outdoor activities and social interaction in a green environment during a pandemic (Xie J., Luo S., Furuya K., \& Sun D., 2020). Barbarossa examined the importance of transportation during the COVID-19 pandemic in Italy to make up for lost time and to start a green revolution that is aimed at quickly decarbonizing urban transport and enhancing cycling and walking through the city (Barbarossa L., 2020). Hamidi highlighted the importance of counties that are tightly linked together through economic, social, and commuting relationships to reduce the number of COVID-19-related deaths (Hamidi, S., Sabouri, S., \& Ewing, R., 2020).

Batty considered the impact of COVID-19 on the global economy, noting it will need time to recover, maybe a generation, and highlighted the importance of using the new technology and document (Batty, M., 2020) he found that in most countries included in the analysis, park visitation had increased since 16 February 2020 compared with visitor numbers prior to the COVID-19 pandemic (Geng, D., Innes, J., Wu, W. et al., 2021). D'Ascanio highlighted the importance of using of graphic, visual, and multimedia contributions to the landscapes that have been generated in the consciousness of the inhabitants through their perceptions during the quarantine and all phases of the pandemic (D'Ascanio, R., \& Mondelli, F. P. editors, 2021). Bravo collected information on this pandemic, including photos and videos. While about $40 \%$ of the global population was under coronavirus lockdown, we announced our brand new initiative called 2020: A Year without Public Space under the COVID-19 Pandemic, which was developed in the early stages to help people cope with the health emergency (Bravo, L., \& Tieben, H. editors, 2020). Honey reported the importance of using public space for recovery during the pandemic, and cities will be shaped because of the social distancing in the landscape (Honey, J., 2021). Broudehoux answered the question: Will the COVID-19 pandemic prompt a shift to healthier cities that focus on wellness rather than functional and economic aspects? The report paradoxically concluded that COVID-19 may also have long-term public health benefits, promoting a more active, self-reliant, and supportive population (Broudehoux, A., 2021). Alsutan stated that the international cases of COVID-19 were high, but in Saudi Arabia, the fatality rate had been very low (about 3.8\%) because of the strict measures applied by the Ministry of Health and the government, which were followed by citizens (Sultan, F. A., 2021). Abdulmajeed reported that schools and universities need guidance in implementing a clear and effective strategy for students to navigate the coming academic year and expand the academic and psychological counseling, especially for vulnerable populations (Alkhamees1, A. A., 2020). Maryam researched the COVID-19 pandemic in Saudi Arabia and noted the importance of having a research center and calling center for COVID-19 data (Awaji, M. A., 2020). Mark considered the effect of COVID-19 on education in Saudi Arabia and found that most of the schools changed to online teaching and learning; the platform, strong Internet, and mobile and computer devices all are available in Saudi Arabia to $90 \%$ of the population, contributing to the success of e-learning education in Saudi Arabia. Mark and Khogali investigated e-learning and teaching in Saudi Arabia. Mark analyzed the effect of COVID-19 on public health, the economy, and migration in Saudi Arabia (Mark, Th., 2021) and (Khogali, H., 2020).

Therefore, we believe that the consequences of COVID-19 pandemic crisis could be even more evident. This Novel research will represent new sources of information regarding the interiorspace, designing the outdoor space, praying in the mosque, visiting the shopping malls, and its psychological effect and occupational aspect on people.

Table 1. Literature and Hypotheses on aspects of impacts

\begin{tabular}{|c|c|c|c|c|c|c|c|}
\hline $\begin{array}{l}\text { Main previous } \\
\text { studies }\end{array}$ & $\begin{array}{l}\text { design of } \\
\text { interior } \\
\text { spaces }\end{array}$ & $\begin{array}{l}\text { design of } \\
\text { outdoor spaces }\end{array}$ & $\begin{array}{l}\text { praying in } \\
\text { mosques }\end{array}$ & $\begin{array}{l}\text { visiting } \\
\text { shoppin } \\
\text { g malls }\end{array}$ & $\begin{array}{l}\text { psychological } \\
\text { effects }\end{array}$ & $\begin{array}{l}\text { Occupati } \\
\text { onal } \\
\text { effects }\end{array}$ & $\begin{array}{l}\text { Research } \\
\text { Output }\end{array}$ \\
\hline & $\begin{array}{l}\text { Duration } \\
\text { time }\end{array}$ & $\begin{array}{l}\text { Health } \\
\text { procedures }\end{array}$ & $\begin{array}{l}\text { psychological } \\
\text { effects }\end{array}$ & & & & \multirow{2}{*}{$\begin{array}{l}\text { *No one of } \\
\text { these } \\
\text { previous } \\
\text { researches } \\
\text { talked about } \\
\text { the duration } \\
\text { time }\end{array}$} \\
\hline & & $\begin{array}{l}\text { Including social } \\
\text { distancing }\end{array}$ & & & & & \\
\hline $\begin{array}{l}\text { (Abid H., \& R. V., } \\
\text { 2020). } \\
\text { (Jaing, S., 2021). }\end{array}$ & & $\begin{array}{l}\text { Social } \\
\text { distancing }\end{array}$ & & \multicolumn{2}{|r|}{ Stress } & & $\begin{array}{l}\text { More health } \\
\text { procedures } \\
\text { are applied } \\
\text { by the } \\
\text { government } \\
\text { in health }\end{array}$ \\
\hline
\end{tabular}




\begin{tabular}{llllll}
\hline $\begin{array}{l}\text { Main previous } \\
\text { studies }\end{array}$ & $\begin{array}{l}\text { design of } \\
\text { interior } \\
\text { spaces }\end{array}$ & $\begin{array}{l}\text { design of } \\
\text { outdoor spaces }\end{array}$ & $\begin{array}{l}\text { praying in } \\
\text { mosques }\end{array}$ & $\begin{array}{l}\text { visiting psychological } \\
\text { shoppin effects } \\
\text { g malls }\end{array}$ & $\begin{array}{l}\text { Occupati Research } \\
\text { onal } \\
\text { effects }\end{array}$ \\
\hline
\end{tabular}

procedures

Reflecting to re-design the interior space and exterior space

(Solution, E. D., Natural Human Health 2020). (Al-Serf, M., ventilation, 2020). smart

(Sameh, S., 2020).

(Echegaray, F., 2020). (Kukenkov, V., 2020). solutions in housing Home design Color

(Scott, J., May 2020). (Gruenwald, H., 2021). (Honey, J., 2021)

(Clouston, S. A., 2021). (Lannoy, L. d., 2020).

(Xie J, Luo S, Furuya K, Sun D., 2020).

(Barbarossa L. 2020). (Hamidi, S., Sabouri, S. and Ewing, R., 2020).

(Batty, M. The

Coronavirus crisis, 2020)

(Geng, D., Innes, J., Wu, W. et al., 2021).

(Corvacho, Helena, June, 2020)

(Jalal, O. M., 2020). (Freeman, Sh., 2020).

(Authority, P. H., 2021) (Health, M., 2021).

(News, A., 2020)

(Blue -Nile., 2020), (Prevention, C. O., 2020),

(WHO, 2020).
-Re shaped the outdoor space

- advertisements

- reducing the

number of

people entering the public park

-transportation

-global economy

-global social

Studying thermal comfort in the outdoor environment
*Change

color

*Maximize

the space

*plants

Practice

positive activities at home

*Check point should be provided

*Redesign the grass with social distancing

*duration time

*study of the environment al issues by ENVI-MET

-Health

procedures

-Social

distancing

Health

procedures

-Social

distancing

-headache,

coughing,

fatigue, a sore

throat, and a

loss of taste or
Positive

action

should be

done

In interior 


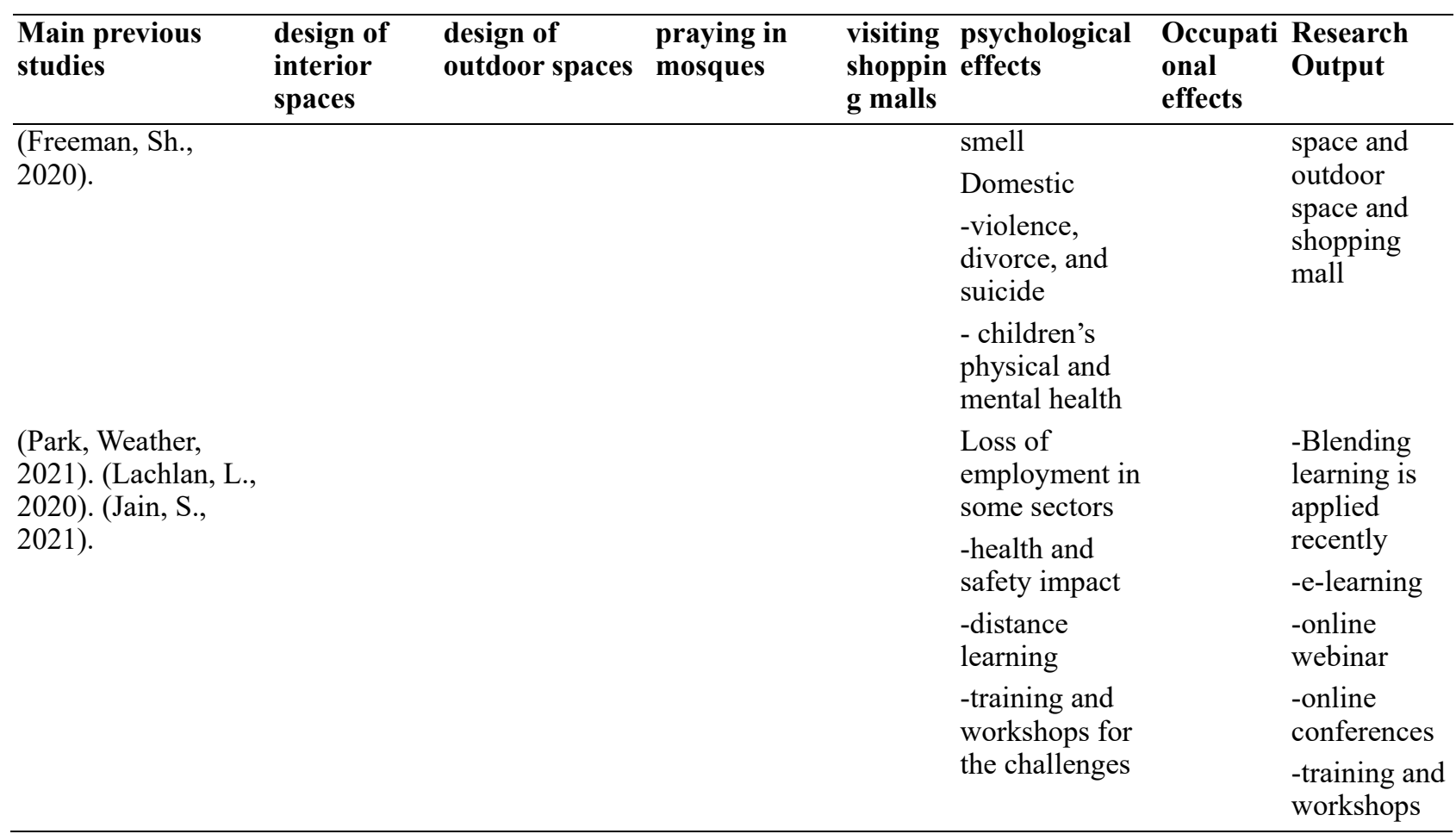

Passing through the literature during the last three years the researcher found that none of these researches discussed the duration time of visiting the shopping mall, visiting the park, and praying in the mosque, so at this point, this research is investigating empirical data in this area. Also, Echegaray, Abid, Jianl, Authority, Health, News investigated the health procedures in general during covid-19, (Echegaray, F., 2020), (Abid H., 2020), (Jalal, O. M., 2020). (Authority, P. H., 2021), (Health, M., 2021), and (News, A., 2021); still, this research will investigate the specific area of activities in shopping mall, outdoor space, indoor space, mosques, psychological occupation, and will discuss the health procedures applied by the government and to which extents they are applied, the smart application could be used to minimize the number of visitors toward these places, smart passport showing if the person has taken the vaccine.

Solution, Al-Serf, Echegaray, and Authority discussed Natural ventilation, smart solutions in housing, home design, using Colour (Solution, E. D., 2020), (Al-Serf, M., 2020). (Al-Serf, M., 2020). (Sameh, S., 2020), (Echegaray, F., 2020) this research will investigate more details on this area such as to maximize the interior space, use of plants, practice positive activities at home.

Some authors like Scott and others discussed reshaping of outdoor spaces, advertisements, reducing the number of people entering the public park, transportation, global economy, global societies. This research will investigate more details in Check point should be provided, redesign the grass with social distancing, duration time, the study of the environmental issues by ENVI-MET. Simulation software (ENVI-met version 4.3, ENVI-MET, Essen, Germany).

Blue -Nile and other authors discussed the negative signs for COVID-19 such as headache, coughing, fatigue, a sore throat, and a loss of taste or smell Domestic, violence, divorce, and suicide, children's physical and mental health (Blue -Nile., 2020), (Prevention, C. O., 2020), (WHO, 2020) and (Freeman, Sh., 2020). On the other hand, this research will investigate the positive activities that could be applied at home or in the out space for better recovery of COVID-19.

\section{Research Methodology}

During the research timeframe from April 2020 to September 2021, a survey was distributed using the Google Forms software. The form recorded the responses from visitors to shopping malls, a mosque, and open spaces. The aim was to collect 282 individuals' responds as a sample for each focus area. In each focus area, there were three main questions about the duration, the health procedures, and the psychological effect of COVID-19. The survey had 15 questions in total. 
Simulation software (ENVI-MET version 4.3, ENVI-Met, ENVI_met GmbH Kaninenberghöhe 2, 5136 Essen Germany) was used to analyze the urban areas and environmental issues (ENVI-MET, 202:1). ENVI-met was used to study the environmental issue in Al Rouda Park in Riyad, Saudi Arabia.

The social life survey was distributed to academics at Dar Al Uloom University, Prince Noura University, and Prince Sultan University; professional groups on social media; students in secondary school. We targeted 282 people from the four areas. There were 141 respondents, including staff members, professors, teaching assistants, students, and professional engineers, which accounted for $50 \%$ of the sample. The survey was distributed again to increase the number of responses during March 2021; 141 responses from people in academia were received.

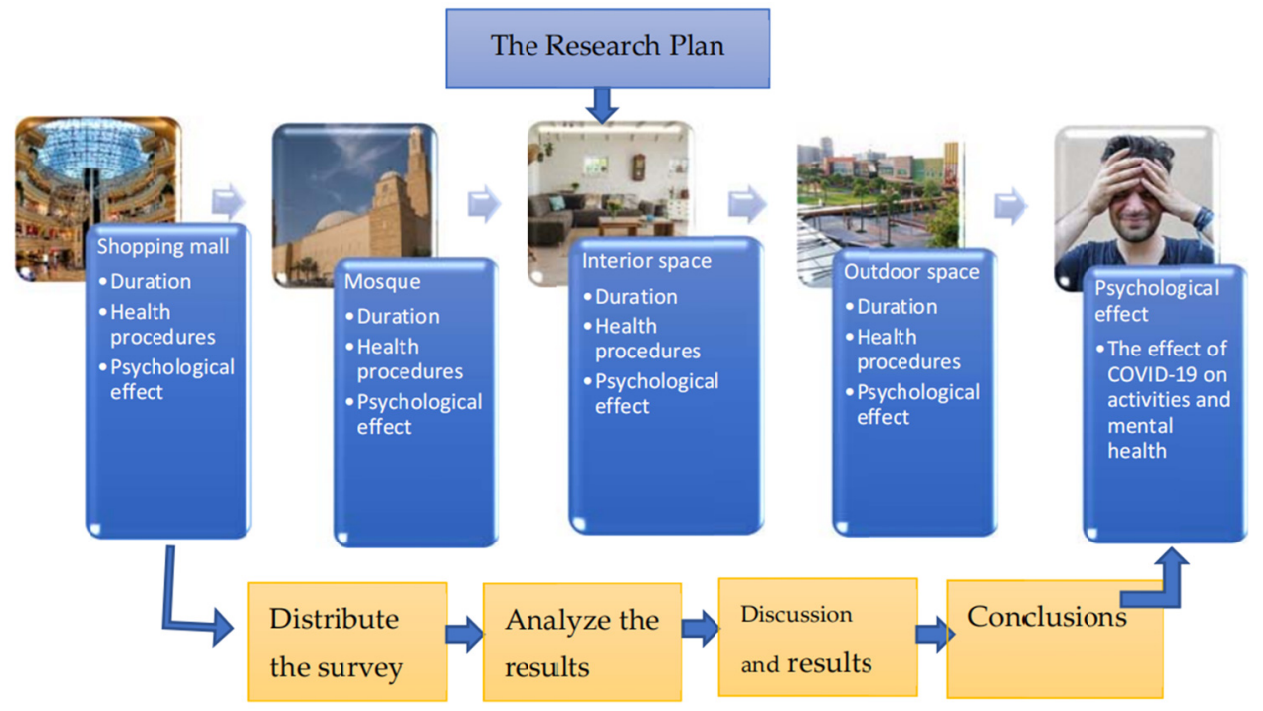

Figure 5. Flowchart of the research method plan to determine the effect of COVID-19 on the social life in Riyadh, including five focus areas: the impact on interior and exterior spaces, mosques, shopping malls, and psychological health

\subsection{Research Hypotheses}

1) COVID-19 is affecting the design of interior spaces.

2) COVID-19 is affecting the design of outdoor spaces.

3) COVID-19 is affecting praying in mosques.

4) COVID-19 is affecting visiting shopping malls.

5) COVID-19 has psychological effects on people.

6) COVID-19 has occupational effects on Academics.

\section{Results}

Figure 6 to 35 shows the results in percentages, distributed amongst the five possible responses: strongly agree, agree, average, disagree, and strongly disagree, more questions were offered. The survey was distributed from 30 September to 30 October 2020. Then, re-distributed during March-2021.

1) The self-reported responses of visitors to a shopping mall during the COVID-19 pandemic were collected. Of the respondents, 92\% applied the health procedures, 50\% would not go inside the shopping mall because they were afraid of contracting SARS-CoV-2, and 5.5\% visited the shopping mall once per week.

2) The self-reported responses of visitors to a mosque were collected. Of all the respondents, $59.5 \%$ would not enter the mosque because they were afraid of contracting SARS-CoV-2, 15\% visited the mosque, $80 \%$ of those that visited applied the health procedures, and $8.5 \%$ of participants visited the mosque once per week.

3) The self-reported responses of visitors to a park were collected. Of all the respondents, $29 \%$ visited the park once per week, $36 \%$ would not visit the park, $17 \%$ applied the health procedures, and $44.6 \%$ would spend time in the park itself because they were afraid of contracting SARS-CoV-2. 
4) The self-reported responses on changing interior spaces were collected. Of all the respondents, $94 \%$ changed their interior spaces, $36 \%$ maximized their interior spaces, and $27 \%$ opened the windows to improve ventilation.

5) People spent their time during the COVID-19 pandemic practicing their hobbies and working from home. Specifically, of all the respondents, $41 \%$ were teaching online, $38 \%$ were watching television, $41 \%$ were using social media more than usual, 30\% were walking, 30\% were reading, 5.5\% were visiting neighbors, $2.7 \%$ were riding a bicycle, and $8 \%$ were listening to the news about COVID-19. The respondents reported substantial hope for the future in terms of the pandemic disappearing and that life would return to normal.

6) The self-reported responses on occupation $40 \%$ of the respondents were practicing teaching online post-covid-19, 20\% they were practicing online webinars, also $4 \%$ were publishing books and $7.8 \%$ were publishing scientific papers, and $23 \%$ were practicing the online webinars. $3 \%$ of the respondents lost their jobs, $19 \%$ of the respondents have no financial resources.

7) The result from simulaton the solar radiation in Figure 39 presented in red is the highest temperature (22 to $25^{\circ} \mathrm{C}$ ) between the block buildings, the orange indicates 20 to $21^{\circ} \mathrm{C}$; the yellow represents $19^{\circ} \mathrm{C}$ to $20^{\circ} \mathrm{C}$, and green is the lowest temperature, between $15^{\circ} \mathrm{C}$ and $19^{\circ} \mathrm{C}$. The prevailing wind direction is northwest, at $8 \mathrm{mph}$, and the humidity is $30 \%$ in March. Figures 6 to 10 show the results of the survey distributed to the Academics.

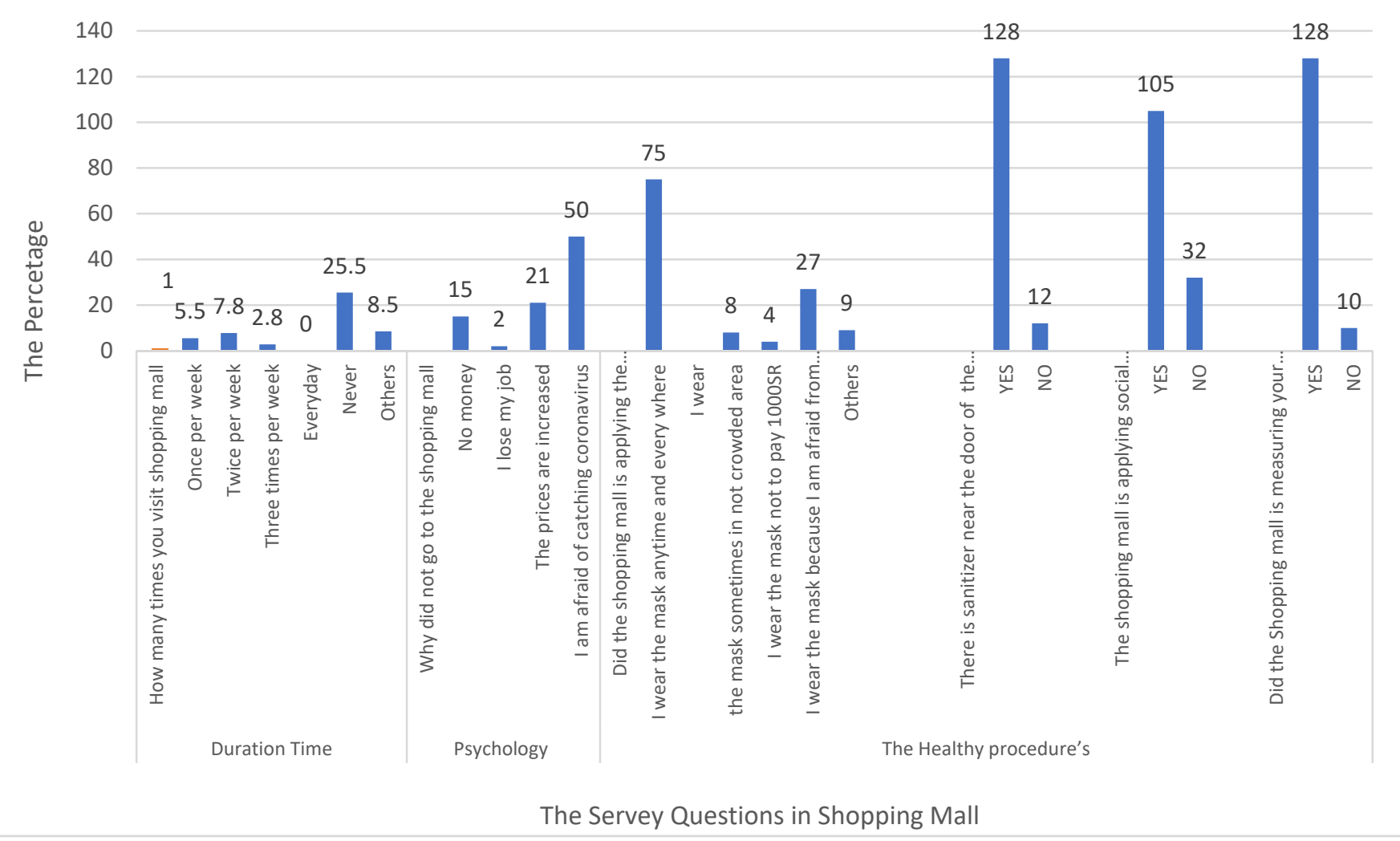

Figure 6. Responses to shopping mall questions during the COVID-19 pandemic 


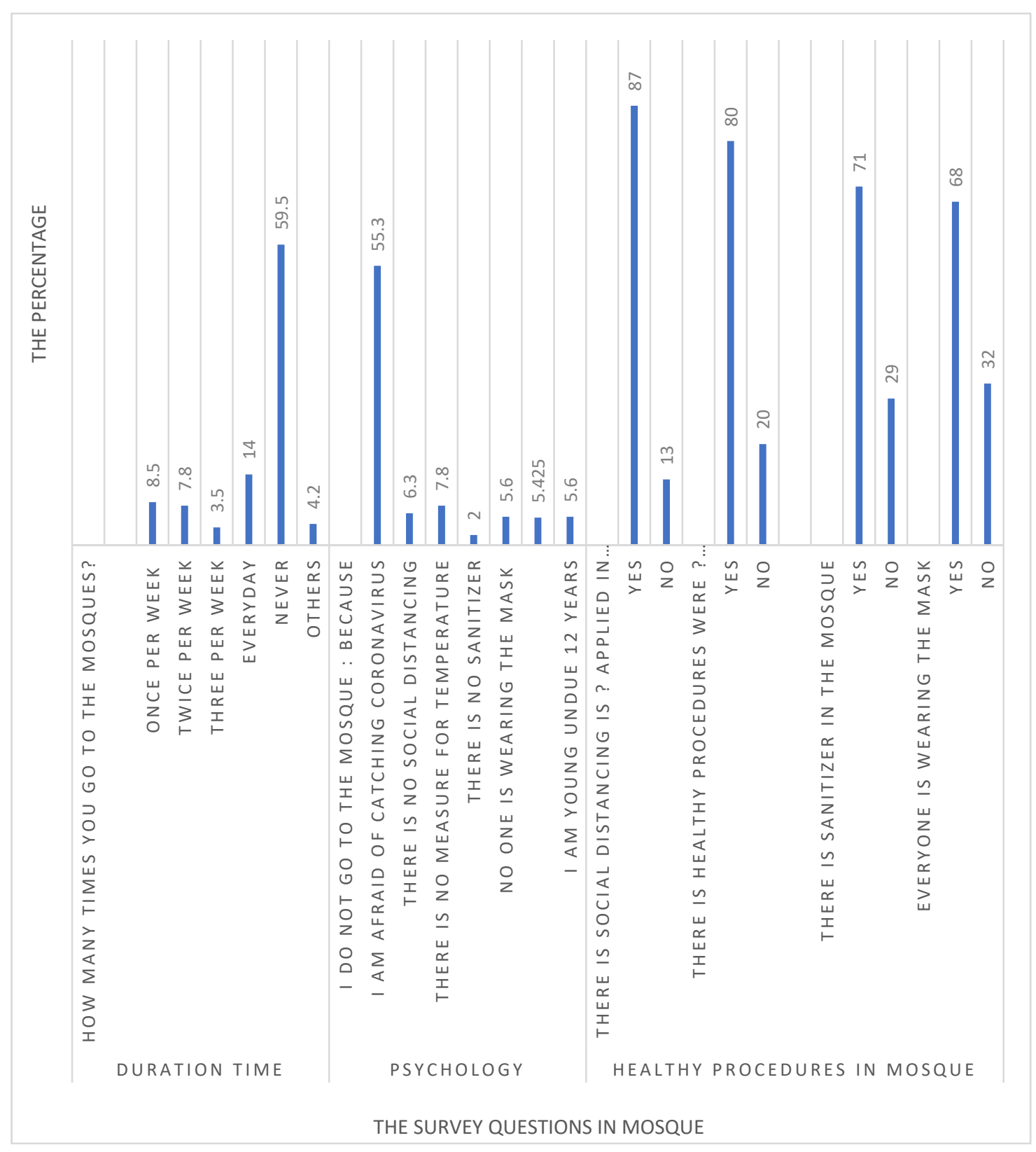

Figure 7. Responses to questions on visiting the mosque during the COVID-19 pandemic 


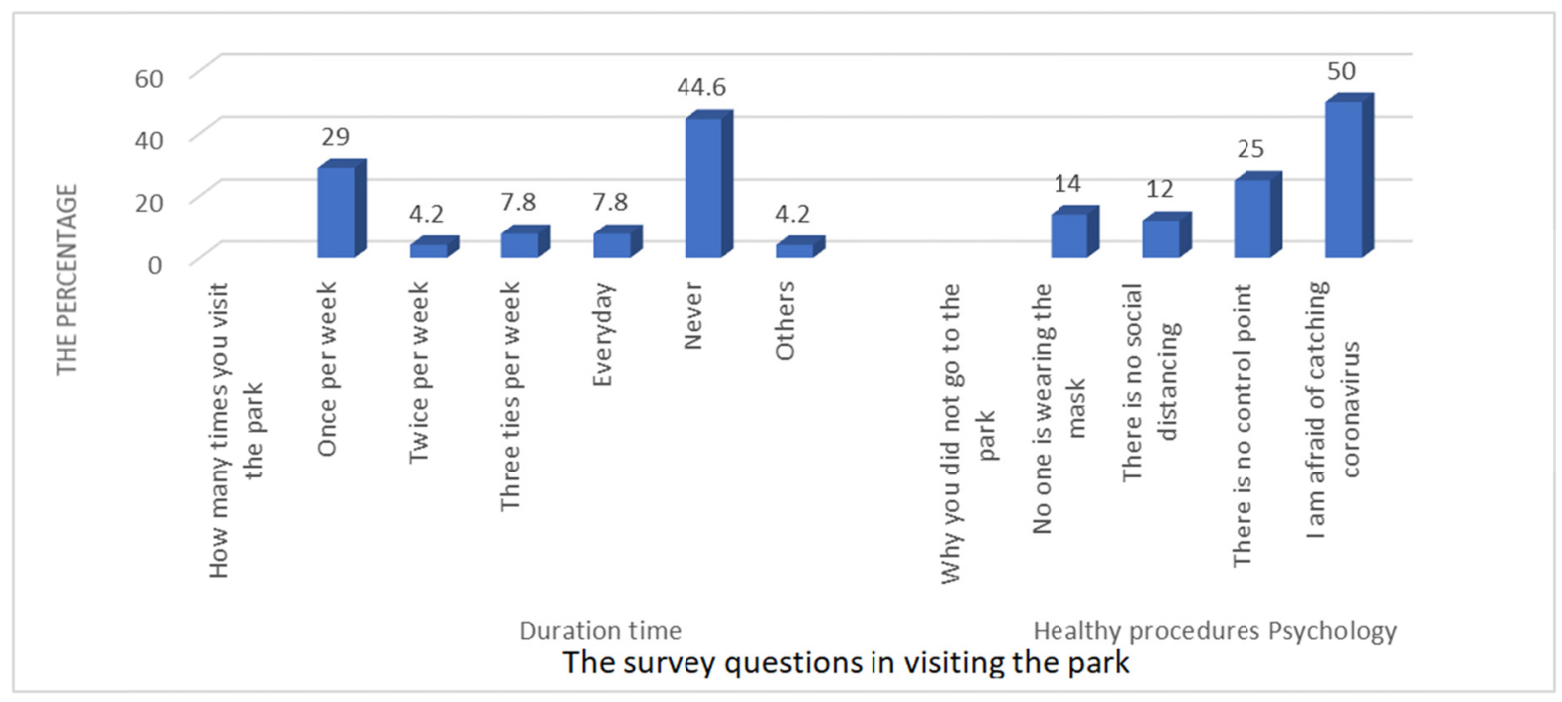

Figure 8. Responses to visiting parks during the COVID-19 pandemic

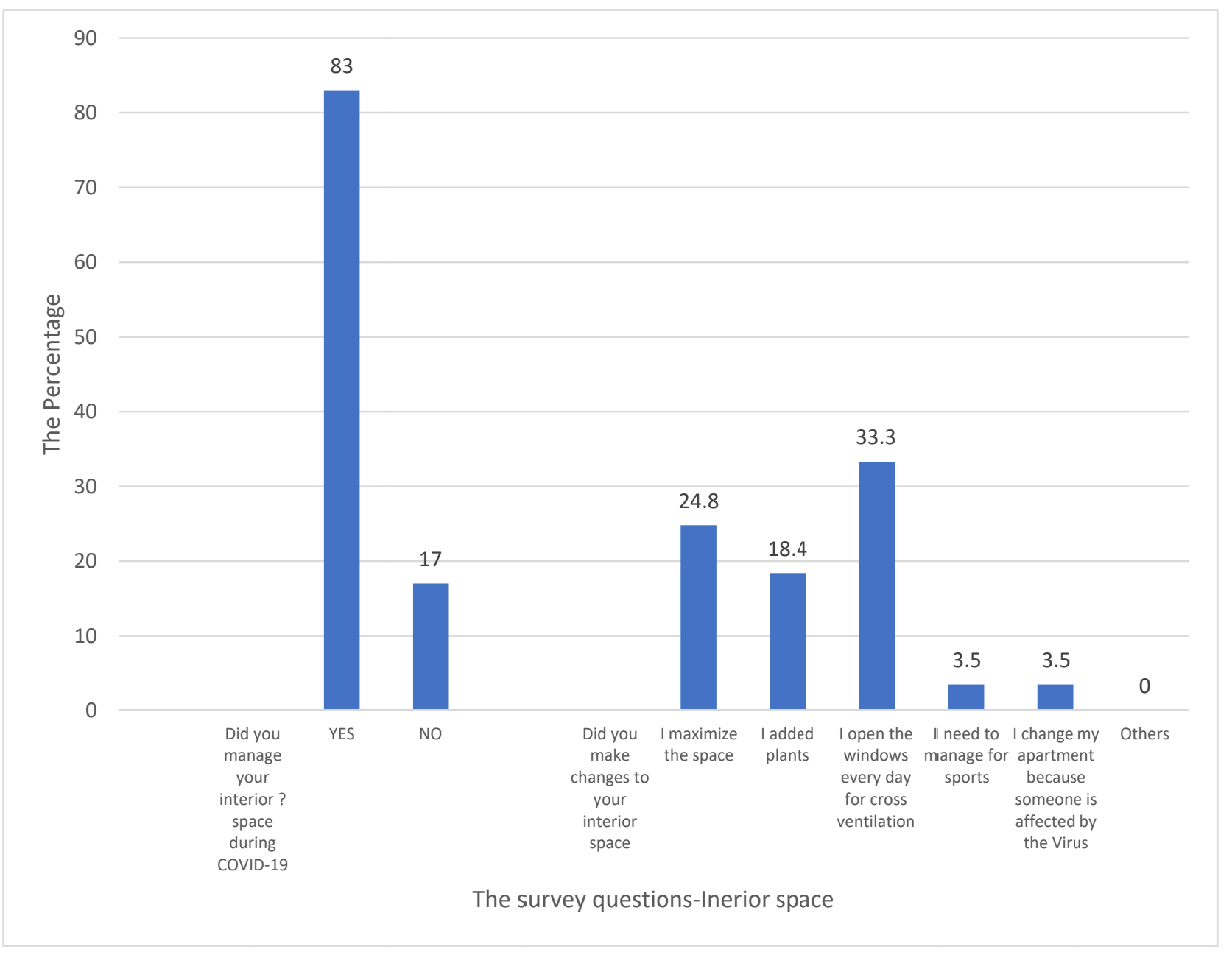

Figure 9. Managing interior space during the COVID-19 pandemic 


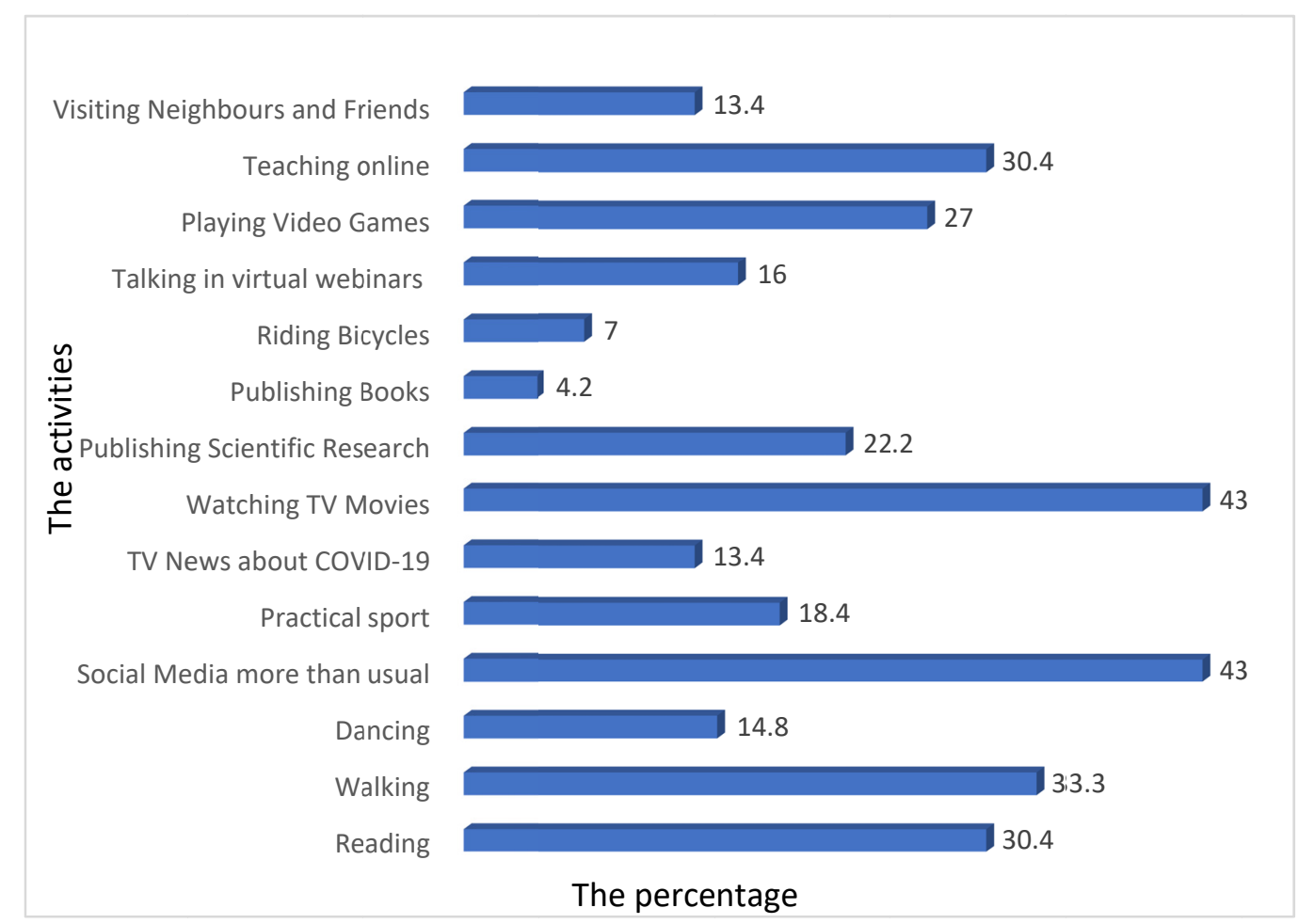

Figure 10. How people spent their time during the COVID-19 pandemic. The psychological and occupation impact

\section{Discussion}

A lockdown was implemented in response to the COVID-19 pandemic continuing during July and August 2020. Some individuals continued to stay at home, while others were slowly resuming their social life. Thus, studying the impact of COVID-19 on people's social lives is crucial, especially regarding the three main activities in Saudi Arabia: visiting shopping malls, mosques, and open spaces.

A survey was distributed on 30 September 2020 and collected on 30 October 2020; it was then redistributed on 15 March 2021 and collected on 31 March 2021 to increase the number of responses. The total number of responses was 141 . The first question was on age. The survey had five groups: 10 to 20,21 to 30,31 to 40,41 to 50 , and 51 to 60 years.

The second question was on professions. Most of the respondents were students, a few were doctors or teaching assistants, while others were lecturers, professors, and engineers, most of the respondent are living in Saudi Arabia and few are living outside Saudi Arabia.

The first focus measured the response of the visitors regarding the shopping malls, mosques, indoor spaces, and outdoor spaces. The survey measured the duration, health procedures, and psychological effects and Occupation.

Alsutan stated that the international cases of COVID-19 are high, but in Saudi Arabia, the fatality rate has been very low because of the strict measures applied by the Ministry of Health and the government and people have followed the instructions (Sultan, F. A., 2021). Through the survey, we found that in six areas (interior and exterior spaces, shopping malls, mosques, parks, and occupation), the health procedures were applied to answer the hypothesis questions.

\subsection{Managing Interior Spaces}

Regarding hypothesis 1: COVID-19 is affecting the design of interior spaces.

(Kukenkov, V., 2020) discussed the organization of the interior space by considering new approaches to the assimilation of researched objects and color-tonal modeling, expanding the scope of the organization of space-associated and structure elements. Their research result agrees with ours.

COVID-19 affected the interior space, most of participants answered yes to the question regarding whether they changed their interior space, while few said no; most of the respondents managed their interior spaces, they added plants, opened windows daily to provide cross-ventilation, and sports activities. The research found that few changed their apartment because someone was affected by the virus. 
During the lockdown due to the COVID-19 pandemic, most people spent their time in their homes. As a reflection of this situation, people could change their interior spaces to fit their everyday activities.

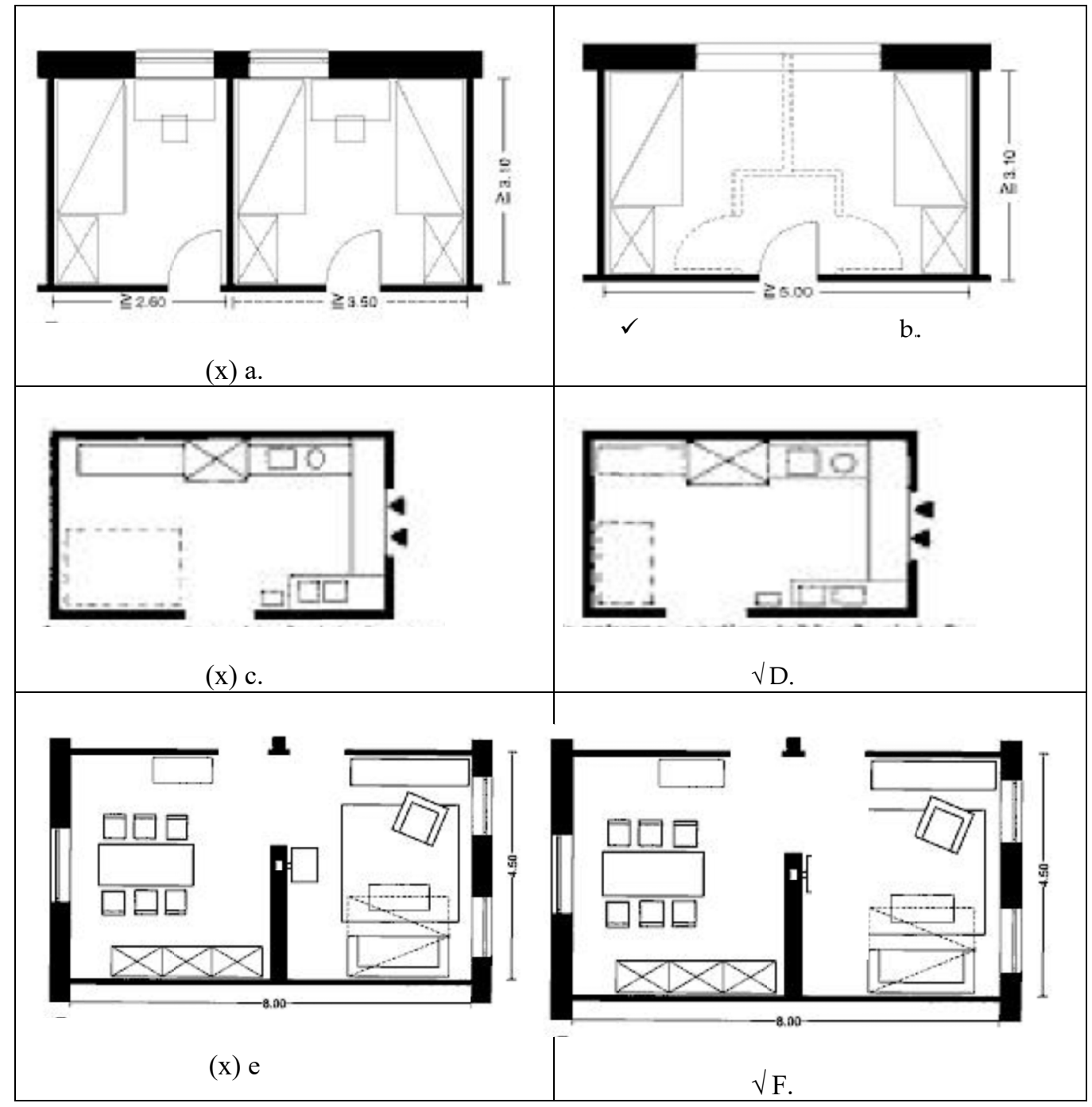

Figure 11. Shows some positive arrangement in designing the interior space

Figure 11 shows some positive arrangements in designing the interior space could be useful during COVID-19, when comparing between $\mathrm{a}$ and $\mathrm{b}$, we found that $\mathrm{b}$ is more comfortable because it provides more space for more activities in the bedroom. Also, when comparing between (c) and (d); we found that (d) is more positive than (c), because when we use small table in the kitchen it provides more space for working. In addition, when comparing between (e) and (f), we found that (f) is more comfortable in the living room than (e) because it provides more space for more activities. In addition, opening the windows for cross ventilation twice during the day it is very important to refresh the air.

The conclusion: humans are adjusting to the circumstances. At the beginning of the lockdown in Saudi Arabia, the government did not allow people to go outside, except for at specific times (curfew), such as to the market or pharmacy, from February to April 2020. People were performing their jobs and sports activities from home and participating in online meetings or webinars. After three months, the government allowed people to walk around in their neighborhood. Daily natural ventilation for one hour in the morning and the afternoon was necessary to change the oxygen inside homes. Additionally, well-being could be increased by maximizing spaces and adding plants. Figure 1 shows the management of interior spaces during the COVID-19 pandemic.

\subsection{Visiting the Park}

Regarding hypothesis 2: COVID-19 is affecting the design of outdoor spaces

COVID-19 affecting our safety and health, (Freeman, Sh., 2020) discussed COVID-19 and outdoor safety in-depth, highlighting solutions such as reducing the number of people entering public parks, staying $2 \mathrm{~m}$ away from others, 
limiting the access to activities, managing the outdoor space, and introducing mental health agencies to deal with COVID-19-related stress. We agree with all these points and we encourage checkpoints at park entrances to check the safety procedures and to encourage people to walk and practice activities in the park. (Clouston, S. A., 2021). This study suggested that outdoor transmission of COVID-19 may occur, noting that the risk of transmission of COVID-19 in the summer was highest on days when the wind was reduced. Our findings agree with this result and we encourage the use of computer programs to study environmental issues. Another study applied ENVI-MET software to study the environmental issues and the solar effects on the surrounding buildings, reporting an increase in the temperature of the building's roof and the facing elevations, suggesting a green buffer zone between buildings and parks, especially high trees. (Freeman, Sh., 2020) and (Lannoy, L. d., 2020) discussed the importance of outdoor space for children and youth, with outdoor play being important for children's physical and mental health; therefore, provincial policies related to COVID-19 and outdoor play are required. We agree with this result. Also, our study of the Al Rouda park, as an example of an outdoor environment, provides a play yard for children and youth, this research is concentrating on the duration time, how many times you visit the park (Figure 8).

(Xie J., Luo S., Furuya K., \& Sun D., 2020) and Barbarossa (Barbarossa L., 2020) discussed the importance of transportation during the COVID-19 pandemic in Italy to make up for lost time and to start a green revolution that is aimed at quickly decarbonizing urban transport and enhancing cycling and walking throughout the city. We agree with this result, as few people were using bicycles, highlighting the importance of walkability and riding bicycles instead of using public transportation to reduce the spread of the pandemic.

Honey noted the importance of using public space for recovery during the pandemic, and that cities will be shaped because of applying social distancing (Bravo, L. \& Tieben, H. editors, 2020). Our findings agree with this result, and we encourage people to practice their activities at home, such as sporting, reading, dancing, painting, watching $\mathrm{TV}$, playing games, and spending time with family. Geng stated that the results for most countries included in their analysis showed that park visitation increased since 16 February 2020 compared with visitor numbers before to the COVID-19 pandemic (Geng, D., Innes, J., \& Wu, W., 2021). D’Ascanio stated that it is important to ask whether the COVID-19 pandemic will prompt a shift to healthier cities that focus on well-being rather than function and economic aspects (D'Ascanio, R. \& Mondelli, F P. editors, 2021). We agree with this researcher regarding this study's focus on health factors in five areas: interior spaces, outdoor spaces, shopping malls, mosques, and psychological effects.

COVID-19 affecting our routine in visiting the park, the research found that most of the respondents reported were never visited the park because they were afraid of contracting SARS-CoV-2. While few reported they visited the park daily. People are encouraged to visit the park and apply the safety procedures. A quarter reported no control point at the park entrances and exits to measure body temperature or check compliance with the health procedures. Figure 8 shows the respondents' responses regarding visiting parks during the COVID-19 pandemic.

5.2.1 Case Study sample in an Outdoor Environment (Al Rouda Park) in Riyadh

Al Rouda Park, with an area of about $3200 \mathrm{~m}^{2}$, is in the middle of Riyadh. 


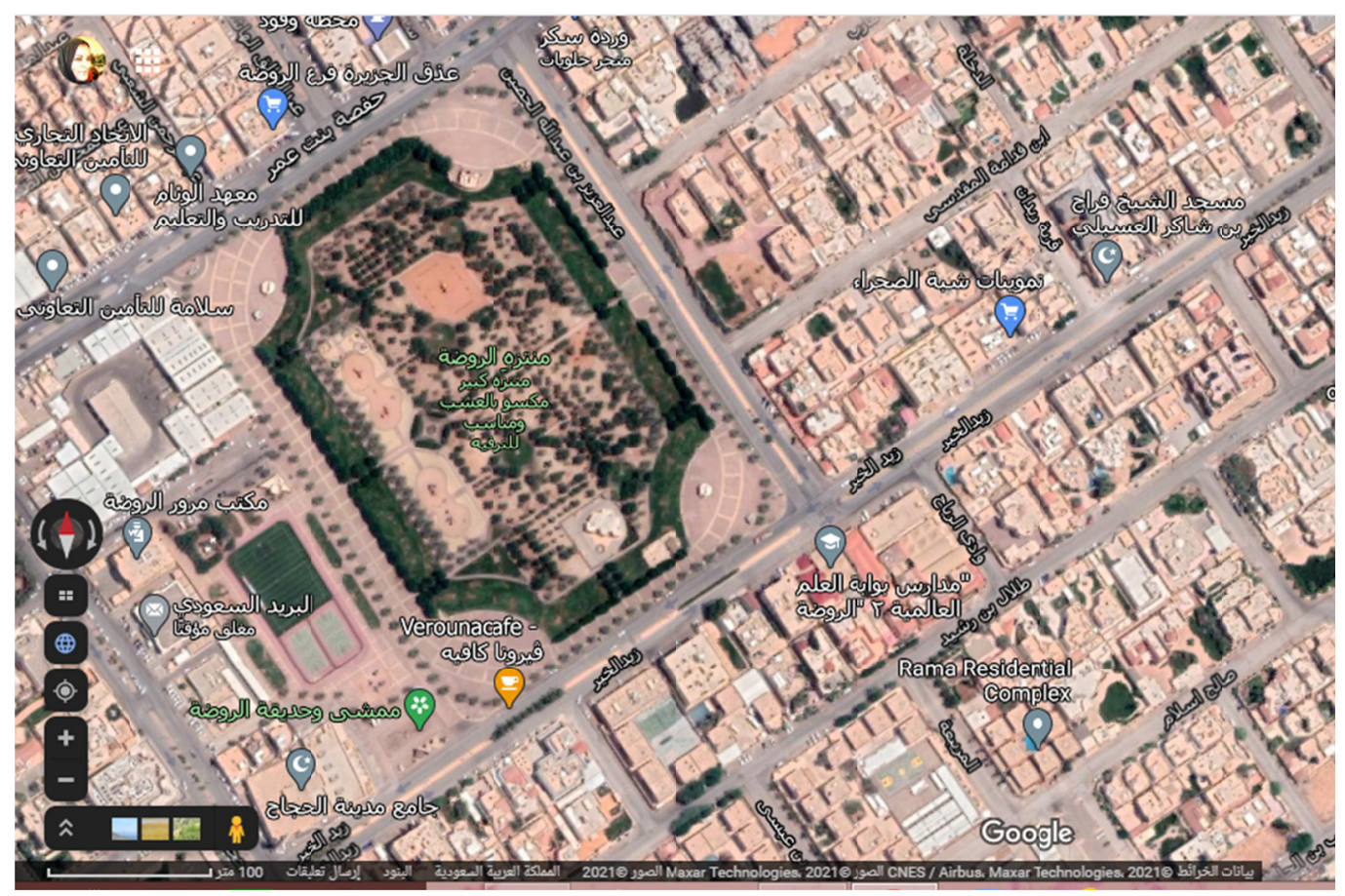

Figure 12. Al Rouda park in the middle of Riyadh is the focus sample for studying the outdoor environment (Google Earth)

The park provides several facilities for children, and adolescents. There is a sports area and a play yard for football and volleyball. Besides, there are children's play areas and there are sitting areas in seats or on the grass. The most important activity that attracts most of the visitors is the walkway around the park.

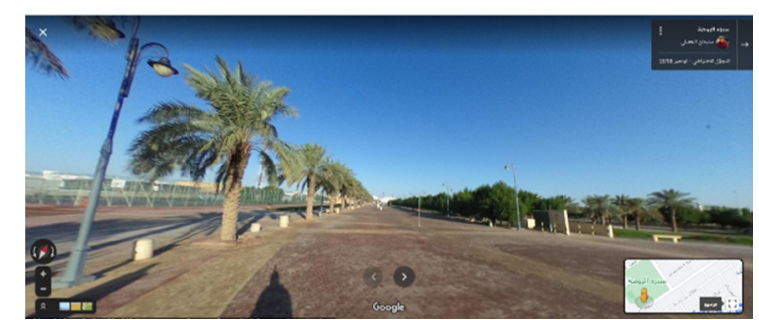

The walkway

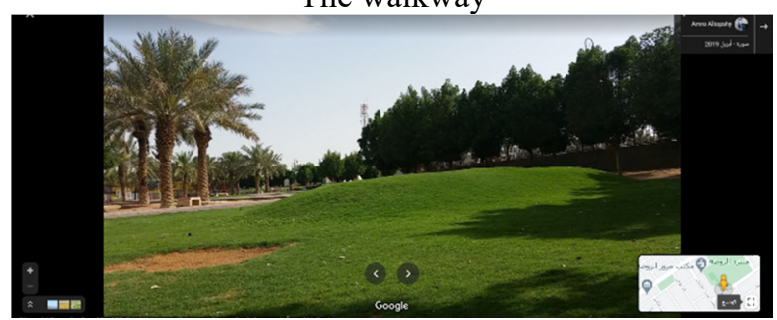

The grass, which is also offered for families

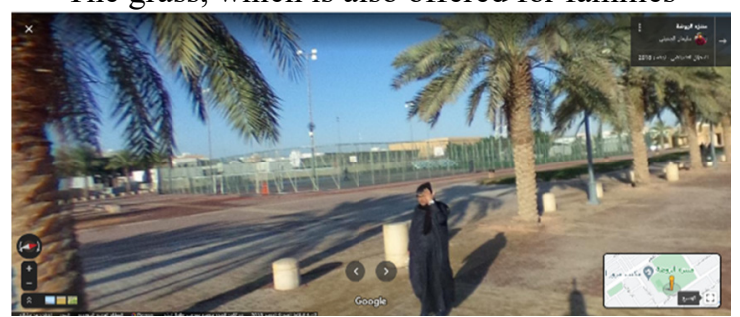

The play yard for sports

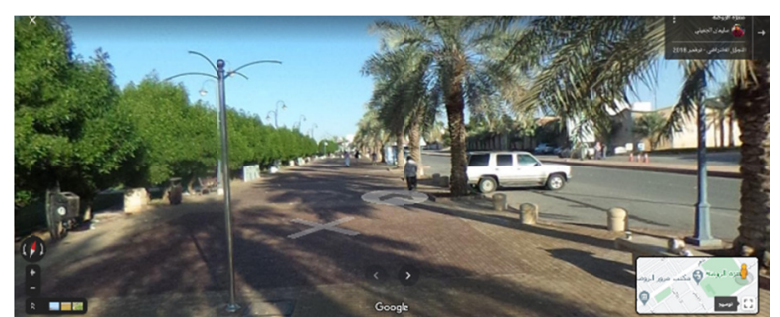

Sitting area
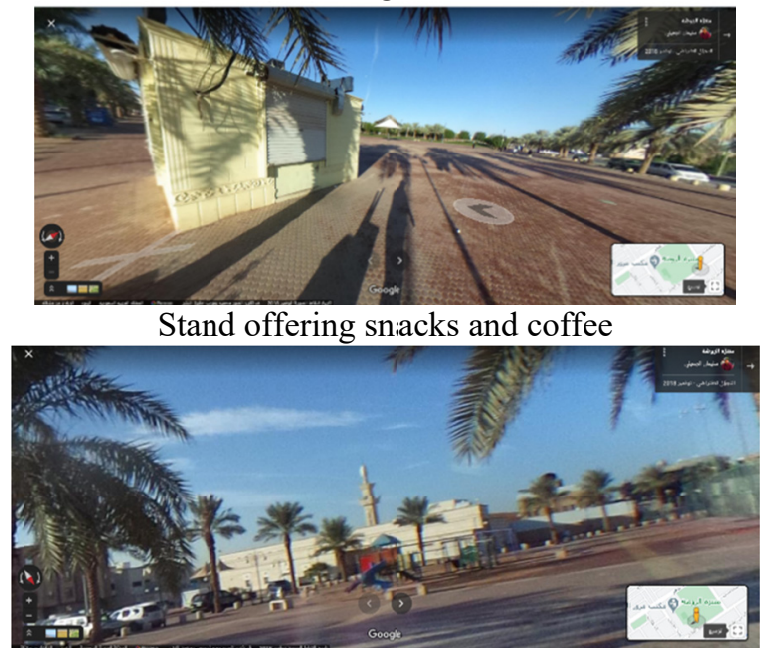

The children's play area

Figure 13. Facilities in Al Rouda Park, Riyadh 


\subsubsection{Environmental Issues}

This section discusses the wide-area hourly average wind vector (speed and direction) at $10 \mathrm{~m}$ above the ground. The wind experienced at any given location is highly dependent on the local topography and other factors, and instantaneous wind speed and direction vary more widely than hourly averages.

The hot season in Riyadh lasts for 4.3 months, from 13 May to 23 September, with an average daily high temperature above $25^{\circ} \mathrm{C}$ to $44^{\circ} \mathrm{C}$ in July. The cool season lasts for 3.0 months, from 26 November to 26 February, with an average daily high temperature below $22^{\circ} \mathrm{C}$ to $7^{\circ} \mathrm{C}$ Figure 38 . The coldest day of the year is 11 January.

The average hourly wind speed in Riyadh displays mild seasonal variation over the year. The windier part of the year lasts for 2.9 months, from 22 May to 17 August, with average wind speeds of more than $8.7 \mathrm{~m} / \mathrm{s}$ per hour. The windiest day of the year is 4 July, with an average hourly wind speed of 10.0 miles per hour. The calmer time of year lasts for 9.1 months, from 17 August to 22 May. The calmest day of the year is 8 October, with an average hourly wind speed of $7.4 \mathrm{~m} / \mathrm{s}$ per hour.

This section also discusses the total daily incident shortwave solar energy reaching the ground over a wide area, considering seasonal variations in the length of the day, the elevation of the Sun above the horizon, and absorption by clouds and other atmospheric constituents. Shortwave radiation includes visible light and ultraviolet radiation. The average daily incident shortwave solar energy displays significant seasonal variation over the year.

The brighter period of the year lasts for 3.5 months, from 12 May to 30 August, with an average daily incident shortwave energy per square meter above $7.4 \mathrm{kWh}$. The brightest day of the year is 21 June, with an average of 8.3 $\mathrm{kWh}$. The darker period of the year lasts for 2.8 months, from 9 November to 2 February, with an average daily incident shortwave energy per square meter below $5.0 \mathrm{kWh}$. The darkest day of the year is 10 December, with an average of $4.2 \mathrm{kWh}$. We based the humidity comfort level on the dew point because it determines whether perspiration evaporates from the skin, thereby cooling the body. Lower dew points feel drier, and higher dew points feel more humid. Unlike temperature, which typically varies significantly between night and day, the dew point tends to change more slowly; thus, although the temperature may drop at night, a muggy day is typically followed by a muggy night. The perceived humidity level in Riyadh, as measured by the percentage of time in which the humidity comfort level is muggy, oppressive, or miserable, does not vary significantly over the year, remaining virtually constant at $0 \%$ throughout the year, i.e., the climate is hot and dry most of the year. Weatherspark (Park, Weather, 2021)

In both summer and winter, people visit parks near their houses. Al Rouda Park is well-designed to encourage daily visitors. The most suitable time for walking, especially during the COVID-19 pandemic, is from 6:00 to 8:00 a.m. and from 4:00 to 6:00 p.m. There are no crowds at these two times. There are no checkpoints to measure personal temperature. 

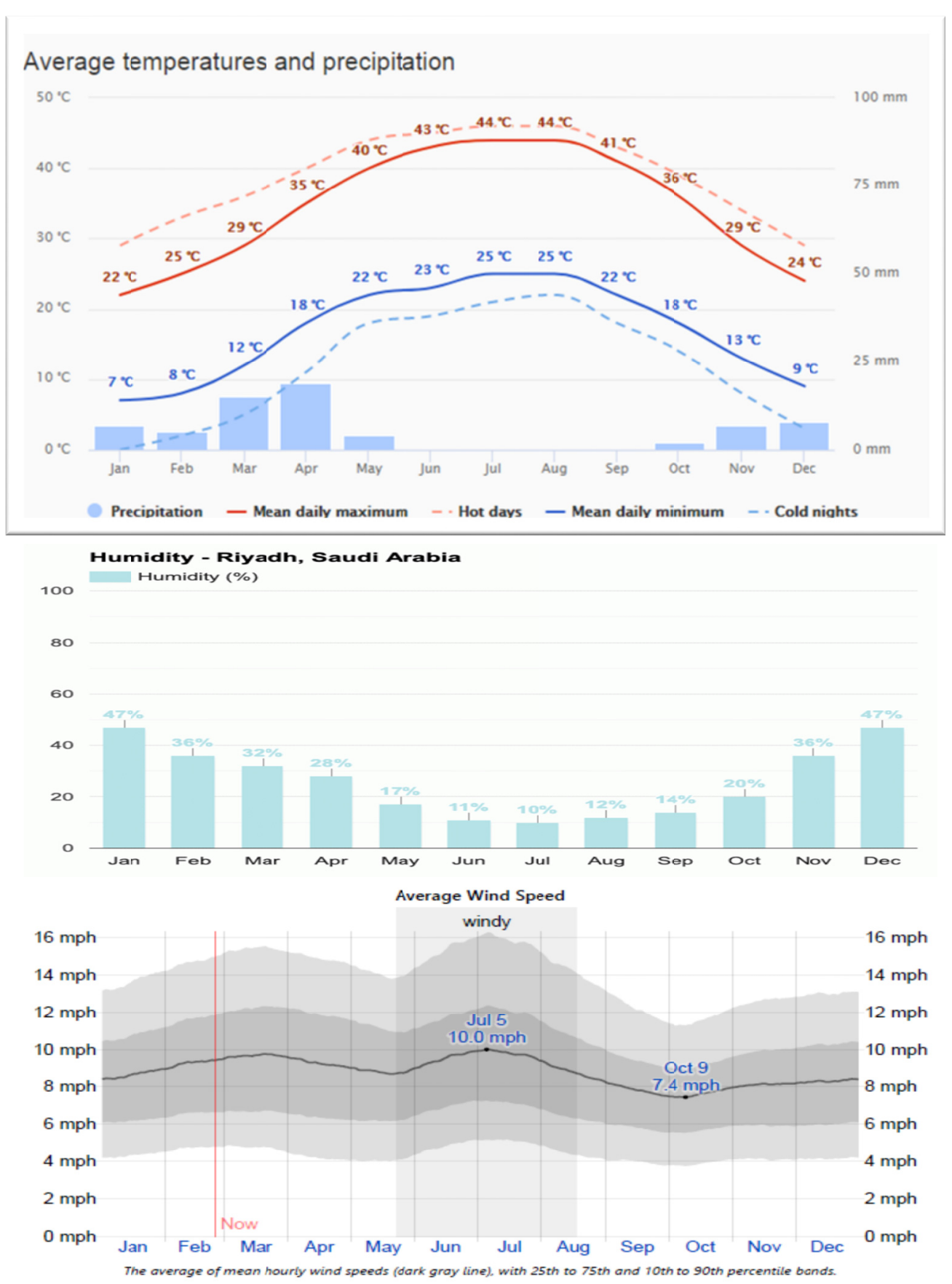

Figure 14. Annual weather variations in Riyadh. Source: Weatherspark (Park, Weather, 2021)

\subsubsection{Simulation by Using ENVI-MET}

Using a simulation program, the thermal image of the park was studied, with wind direction, and temperature at the microscale. For example, ENVI-MET software is a program used in the design phase that helps to reduce the urban heat surrounding the park by adding more trees and water features. 


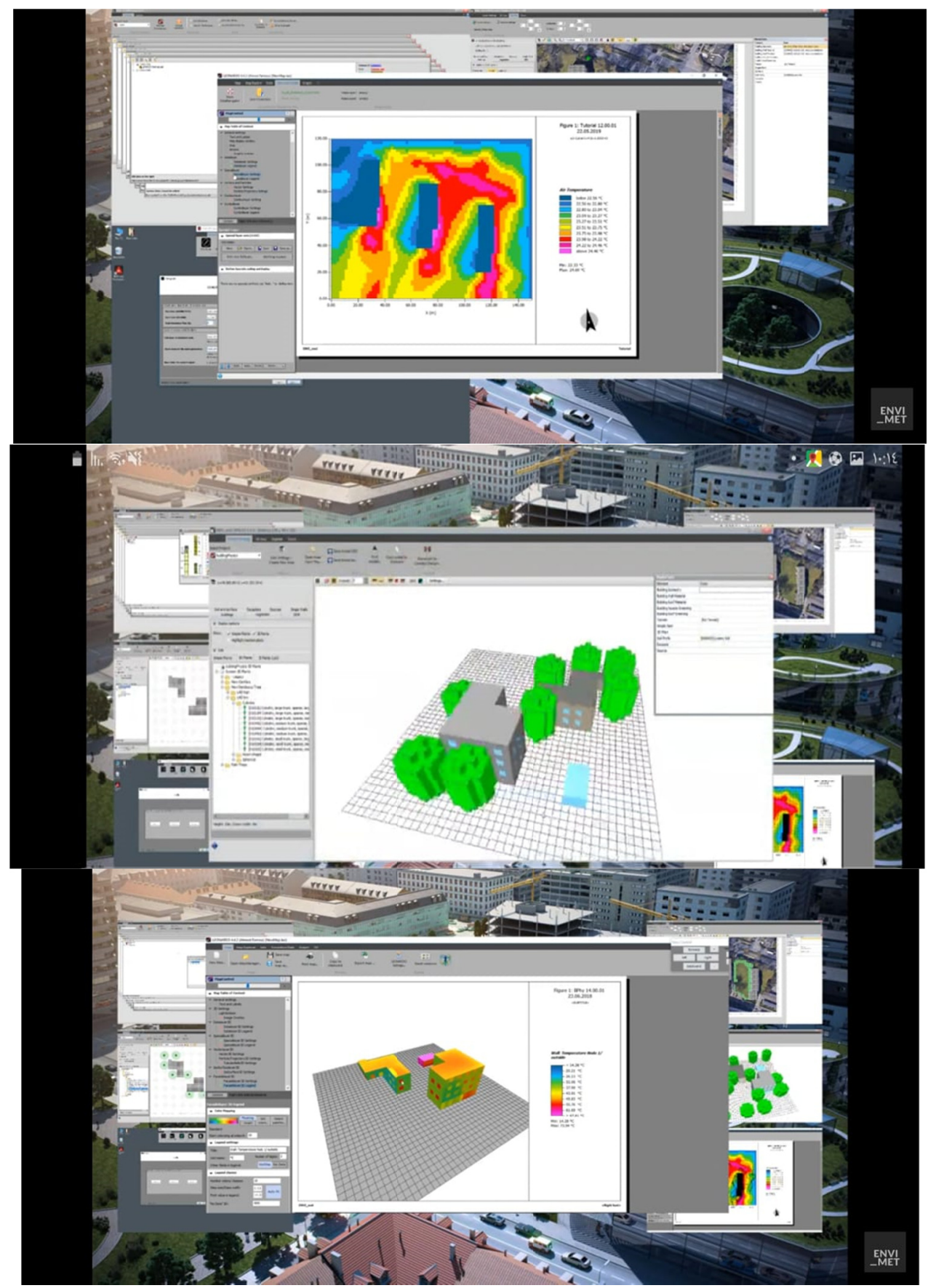

Figure 15. ENVI_MET (ENVI-MET, 2021) software program analyzing environmental issues

ENVI-MET software was used to study the environmental issues in the park, such as temperature, humidity, wind direction, and solar radiation, to identify potential solutions for exceeded temperature especially in summer such as planting tall trees to create a buffer zone between the buildings and the park to reduce the temperature.

The solar radiation in Figure 15 presented in red is the highest temperature $\left(22\right.$ to $25^{\circ} \mathrm{C}$ ) between the block buildings, the orange indicates 20 to $21^{\circ} \mathrm{C}$; the yellow represents $19^{\circ} \mathrm{C}$ to $20^{\circ} \mathrm{C}$, and green is the lowest temperature, between $15^{\circ} \mathrm{C}$ and $19^{\circ} \mathrm{C}$. The prevailing wind direction is northwest, at $8 \mathrm{mph}$, and the humidity is $30 \%$ in March. It is important to plant high trees as a buffer zone between the park and the surrounding buildings to minimize the temperature, especially in summer.

The recommended health procedures regarding COVID-19 in parks include checkpoints near the main gate and main entrance. Notably, most parks in Riyadh, such as Al Rouda Park, have not had checkpoints during the COVID-19 pandemic. 
- $\quad$ The Tawakkalna application was implemented by the government for entrance to all public spaces, which should be downloaded on personal mobile phones and presented at the checkpoint to ensure that a visitor is not infected with the virus (Prevention, C. O., 2020),

- Checkpoints in parks should be provided during the COVID-19 pandemic to ensure the health procedures are being applied, such as checking personal temperatures using smart devices and wearing a mask.

- People, including children and youth, should visit the park weekly for walking and practicing sports, as fresh air is required for their health, especially during COVID-19.

- $\quad$ People should be encouraged to use bicycles within their neighborhoods.

- Software such as ENVI-MET should be used to study environmental issues, such as temperature, humidity, wind direction, and solar radiation to provide solutions for exceeded temperature especially in summer furthermore, tall trees should be planted to create a buffer zone between the buildings and the park to reduce the temperature.

- Outdoor fans should be used in summer to increase the walkability of Riyadh.

- Health procedures should be applied to all park visitors.

- Some effective design solutions should be applied in the park such as, Figure 16 shows some effective solutions in designing the park during COVID-19 by applying the social distancing in the seats (b), Amphitheatre (e), drawing circles in the grass for families with social distancing (a), and drawing specific path for walking and running(d). Figure 16 shows some effective solutions in designing the park.

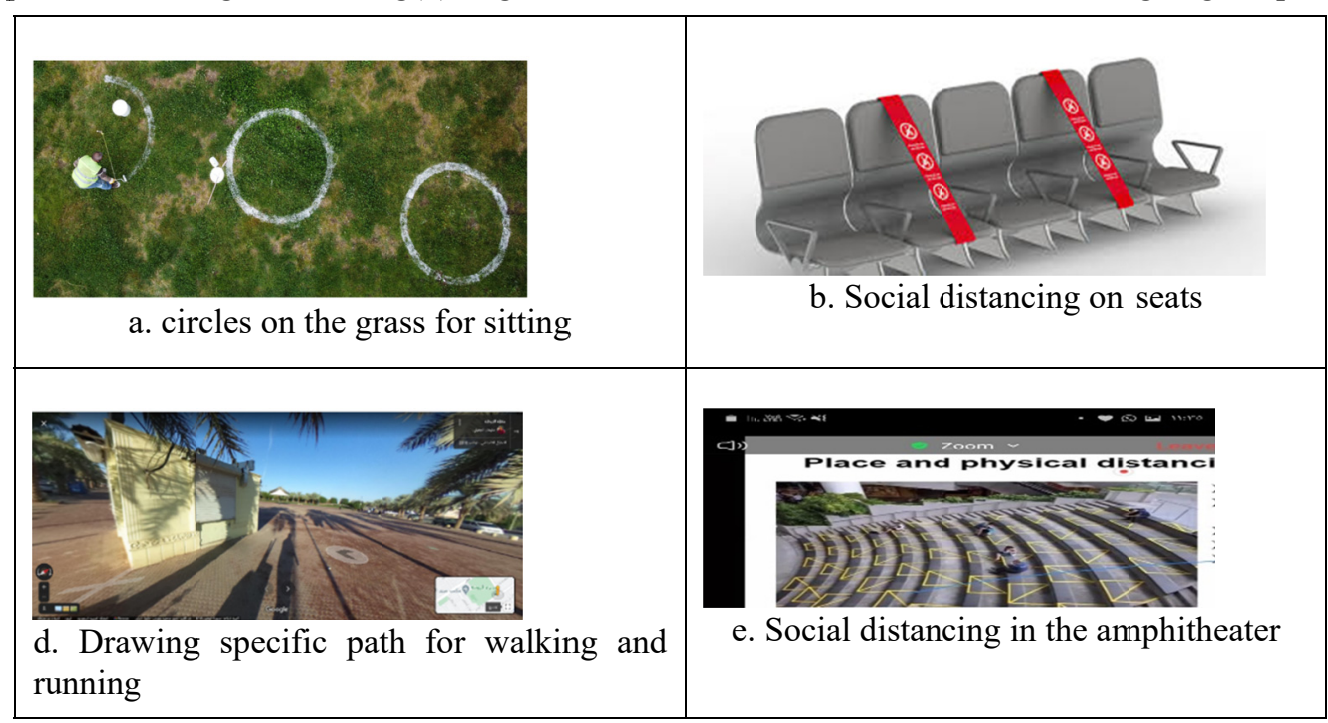

Figure 16. Shows some effective solutions in designing the park post-COVID-19

\subsection{Mosques}

Regarding hypothesis 3: COVID-19 is affecting praying in mosques.

COVID-19 affected visiting the mosque, more than half of the respondents reported they never visited the mosque because they were afraid of contracting COVID-19.

Other's respondents reported visiting the mosque once per week, some visited the mosque twice per week, others visited the mosque three times per week, and a few visited the mosque daily. Table 2 shows the duration time of the respondents visiting the mosque, few people visited the mosque every day or per week, and this mean that COVID-19 strict people to practice their everyday activities.

Table 2. Shows the duration time of the respondents visiting the mosque

\begin{tabular}{lllllll}
\hline Duration time/week & Once a week & Twice a week & Three times a week & Every week & Never go & Others \\
\hline Number of visitors & 12 & 11 & 5 & 20 & 84 & 6 \\
\hline
\end{tabular}

Respondents reported that health procedures were applied in the mosques, such as the measurement of temperature, providing sanitizer, and wearing masks. Few of respondents reported not attending because they were under 12 years old. 
Thus, health procedures were being applied in the mosque and, figure 7 shows that most of the respondents said that social distancing was applied in the mosques, Figure 17 shows the social distancing between the prayers about $2 \mathrm{~m}$ as distance. Each prayer brings his own Sigada. Also, the total number of visitors is decreased per hour. The public awareness of the health procedures has increased.

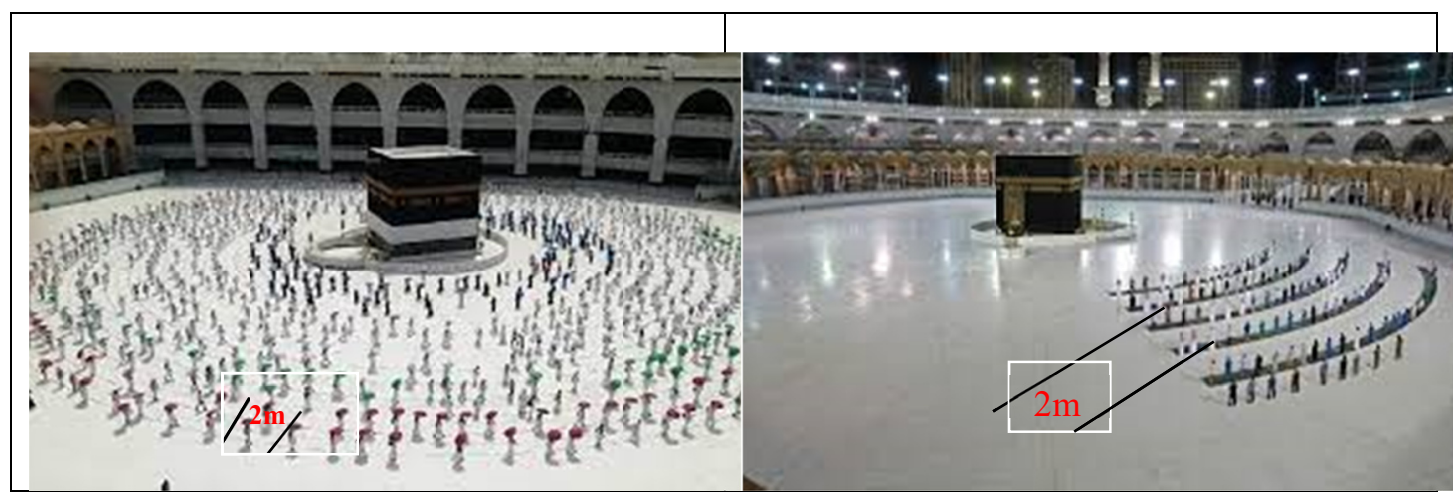

Figure 17. Shows the social distancing between prayers about $2 \mathrm{~m}$ in the mosques

\subsection{Shopping Malls}

Regarding hypothesis 4: COVID-19 is affecting visiting shopping malls.

COVID-19 affected visiting the shopping mall, half of the respondents agreed that they did not visit shopping malls because they were afraid of COVID-19 affecting our daily rotine, most respondents reported visiting the shopping mall once per week, other respondents said that they did not visit the shopping mall (Table 3) because of financial issues, a few answered that they lost their job, while others reported that prices had increased. For the health procedures. Most of the respondents reported sanitizer being placed near the front door of the shopping mall. Most of the respondents reported that social distancing were applied in the shopping malls. Also, respondents reported measurements of body temperature by a smart meter at the front door were applied, and few of the respondents reported that their temperature was not measured at the front door. Figure 6 shows the results of the respondents for the shopping mall questions:COVID-19 affecing our safety and health. Table 3 Shows the duration time of the respondents visiting the shopping mall, the results show that zero vistors the shopping mall everyday, and most of the respondents visted the shopping mall once per week, this mean that COVID-19 stric people to practice their everydayactivities.

Table 3. Shows the duration time of the respondents visiting the shopping mall

\begin{tabular}{lllllll}
\hline Duration time/week & Once a week & Twice a week & Three times a week & Every day & Never go & Others \\
\hline Number of visitors & 78 & 11 & 4 & 0 & 36 & 6
\end{tabular}

Figure 4, photo (a) shows the social distancing is applied in shopping malls, also most of shopping malls design reception room to apply the health procedures such as testing the temperature by smart device and wearing the mask. In addition, the numbers of visitors are decreased per day.

\subsection{Psychological Effects}

Regarding hypothesis 5: COVID-19 has psychological effects on people.

COVID-19 affected our health, more than half of the respondents said that they were affected by COVID-19. COVID-19 affected our family functions and relations they described their family as functioning much better, few said that their family functioned much worse during their infection, and few reported no difference in their family's functioning. Others reported that their family provided support for them, and more than half said the family support was a little better. Also, they reported that they were in a good mood, others of the respondents stated that the family support was no more than usual, and others reported that the family supported them as much as they usually did and had average feelings. More than half were not losing confidence and few reported average feelings.

COVID-19 has psychological effect, more than half of the respondents reported that they did not visit parks, shopping malls, or the mosque because they were afraid of COVID-19.

COVID-19 affected our daily activities, the last question in this part was about engaging in hobbies at home during and after the lockdown. Of the respondents, more than quarter started reading, walking, or dancing; others used 
social media more than usual; a few took part in sports. Also, they listened to the news on the television about the COVID-19 pandemic, others reported watching movies on television, a few of the respondents said they published scientific research, and few published books.

Notably, a few reported riding bicycles. This finding has two meanings: riding bicycles is uncommon in Saudi Arabia and that people spent most of their time at home.

The respondents said that they participated in webinars, taught online, and/or were playing video games, and a few were visiting neighbors. Thus, people rarely visited each other during the COVID-19 pandemic.

Figure 10 shows the results of how people spent their time during the COVID-19 pandemic. They were practicing their hobbies, such as reading, sporting, walking, and writing.

When comparing the results for the five areas, more than half of the respondents reported that they were not visiting these areas because they were afraid of contracting COVID-19. Although the survey was distributed twice, in April 2020 and in March 2021, despite one year passing, the results were still the same: more than half were still afraid of contracting COVID-19. Here, we studied the psychological effects of COVID-19 on people, and it found that it has deeply affected people it constrains them to come back to their social life, most of the respondents reported that because they were afraid of being affected by the COVID-19. We encourage people to practice their hobbies in the interior space and exterior space.

The last question on the survey was an open question. People wrote their opinions on the effects of the COVID-19 pandemic on social life. One respondent said: "May God keep the epidemic from us, and may God heal their patients, and have mercy on their dead ... Oh God, Amen.” Others responded as noted in Figure 18.

First, I think covid-19 changed a lot of things in our life during the quarantine or also now after the quarantine, so now you can do your hobbies normally as before, but you must be careful.

Keep yourself

I scared from death

Nothing

I think the COVID-19. Will disappear soon and our life will be better. Thanks

Figure 18. Some responses of the survey respondents to the open question. How did you spend your time at home during the COVID-19 lockdown

\subsection{Occupational Aspects}

Regarding hypothesis 6: COVID-19 has affected the occupational aspect.

Fifty percent of the respondents reported that they were practicing teaching online post covid-19.

While about quarter they were practicing online webinars, also, few were publishing books and others publishing scientific papers, and less than quarter were practice the online webinars. When asking the respondents, why you did not visit the shopping mall? Few of the respondents reported 'Because I lose my job', other reported 'I have no money'.

COVID-19 affected the work condition for example schools and universities. During the lockdown in April to May 2020, Saudi Arabia applied e-learning in schools and universities as a special situation. Now we come back to universities and applied the blending learning from September to April 2021. This highlights the importance of applying training program to teachers to face these challenges in the accessibility, new teaching strategies in the online teaching and learning, Quality Matter principles, improvement of the Student Management system (LMS).

COVID-19 has deep psychological effect on people, half of the respondents reported they were never visiting the shopping mall, the mosques, and the park because they were afraid from covid-19, they should practice positive activities while they are staying home.

COVID-19 has deep impact on the workplace, in safety and health procedures such as social distancing, wearing the mask, measuring the temperature by smart devices. Table 4 shows the effect of COVID-19 on occupational aspect and the best practice. 
Table 4. The effect of COVID-19 on occupational aspect and the best practice

\begin{tabular}{ll}
\hline The effect of COVID-19 in occupational aspect & The best practice \\
\hline COVID-19 affect our health & $\begin{array}{l}\text { Apply the health procedures, such as wearing the mask, } \\
\text { measure the temperature by smart device }\end{array}$ \\
& $\begin{array}{l}\text { Apply software to check your health situation like } \\
\text { Tawakkalna } \\
\text { Going into online teaching and learning, online } \\
\text { marketing }\end{array}$ \\
COVID-19 affect our workplace & $\begin{array}{l}\text { Searching about other online opportunity such as online } \\
\text { teaching, online marketing, conference moderator. }\end{array}$ \\
COVID-19 affected our daily routine & $\begin{array}{l}\text { Practice daily activities at home such as } \\
\text { Sporting, writing, attending webinars, attending } \\
\text { conferences, practice your hopies }\end{array}$
\end{tabular}

Table 5. The results for the five focus areas: interior space, exterior space, mosques, mall, psychological effects, as well as the three focus questions about the duration, health procedures, psychological effects in March 2021

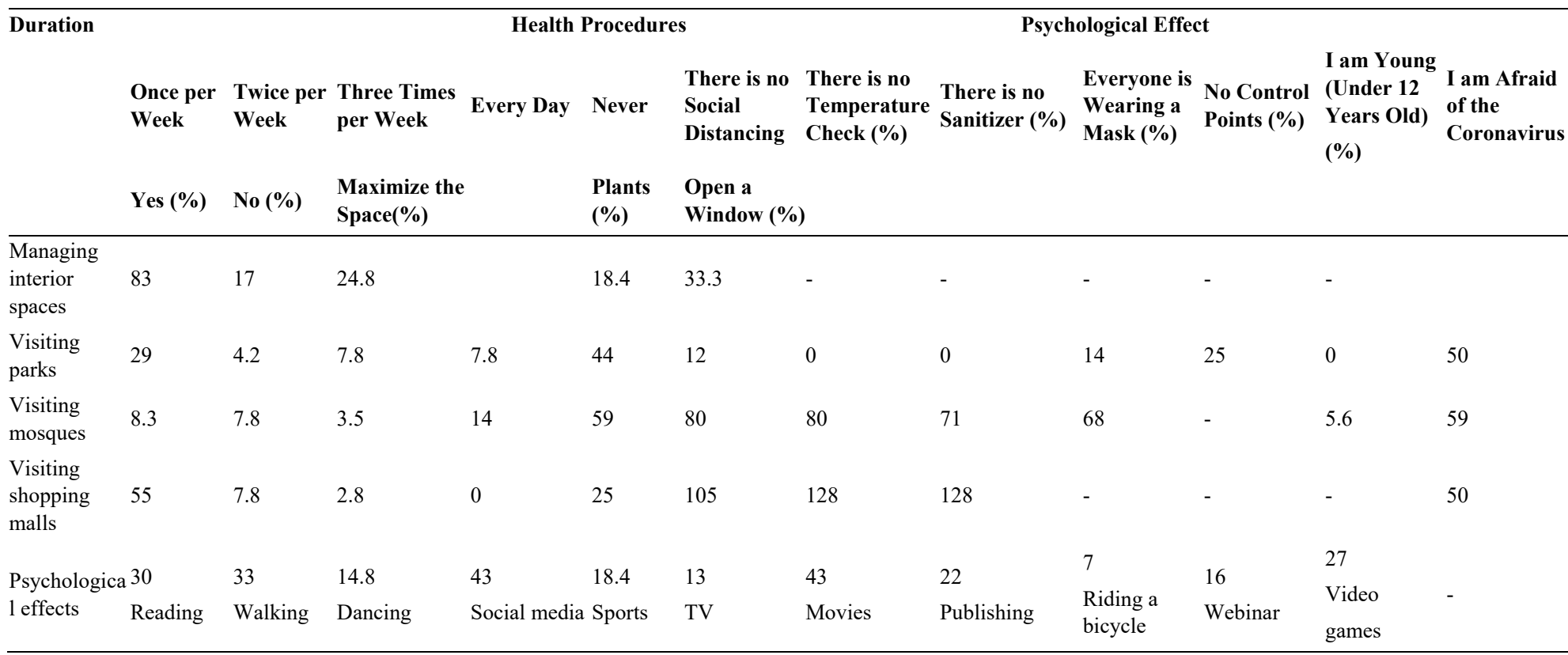

Notable recommendations include:

- $\quad$ People should continue participating in activities and planning for their family and children's future.

- $\quad$ People should be encouraged to apply health procedures when visiting shopping malls: social distancing, using sanitizer and wearing a mask.

- People are encouraged to go outside, visit parks, and practice walking and sports while applying the health procedures.

- Additionally, this research encourages people to visit mosques or churches regularly and to apply health procedures.

- We also recommend that people think positively and manage their time at home by practicing sports, reading, writing, managing their indoor spaces by opening the windows twice per day for good ventilation, adding plants, and working at home.

- People should continue to learn the new technologies in e-learning, accessibility. 


\section{Future Resources}

Future research is recommended in these three areas because of the lack of studies identified in the concerned literature:

1) The effect of COVID-19 on Economics.

2) The psychological effect of COVID-19 on children and students.

\section{Conclusions}

This study was conducted during the post-covid-19 period in Riyadh, Saudi Arabia, to study the effect of COVID-19 on academic social life. Six focus areas were studied: shopping malls, mosques, interior spaces, exterior spaces, and the psychological effects of the COVID-19 pandemic on occupation aspect. Mosques were applying health procedures by testing temperatures near the entrance doors and applying social distancing measures, and mask-wearing was practiced by most visitors. Most respondents reported changing their interior spaces to fit their everyday activities. The research encourages people to visit the park every day, shopping mall weekly, the government should apply social distancing in seats and grass, control point to check the health procedures by smart devices, the respondents said that to increase their well-being, they practiced activities at home, listening to the news about COVID-19 on television, playing video games. Notably, the respondents rarely visited each other during the pandemic. Regarding the occupation aspect people should keep learning new skills to fulfill the new Challenges by COVID-19. We believe that much research could be done in COVID-19 in the future.

\section{Acknowledgement}

The Researcher would like to acknowledge Dar Al Uloom University, especially the Deanship of Post Graduate studies and Scientific research for funding this research and to my students in course Environmental Control, DAU staff, PNU Staff and PSU Staff for filling the survey. My Thanks should be extended to Dean of College of Architecture and Digital Design and to Arc Scientific Research.

\section{References}

Abid H., \& R. V. (2020). Effects of COVID 19 Pandemic in Daily Life. Current Medicine Research, and Practice.

Alkhamees1, A. A. (2020). The Psychological Impact of COVID-19 Pandemic on the Students of Saudi. The Open Public Health Journal, 14, 12-23. https://doi.org/10.2174/1874944502114010012

Al-Serf, M. (2020). How Can IOT Support Sustainability in Mena. Riyadh City, 00966, Saudi Arabia. Retrieved from https://youtu.be/xSaUytTmN0U

Al-Serf, M. (2020). Implementation of Green Building in Saudi Arabia. Riyadh City. Retrieved from https://youtu.be/FpZjVkSgJO8

Authority, P. H. (2021). Mosques Protocole. Retrieved from https://covid19.cdc.gov.sa/professionals-health-workers/preventive-protocols-from-29-10-1441/mosque-pro tocols-en/

Awaji, M. A. (2020). Pandemic of Coronavirus (COVID-19) in Saudi Arabia. Prepints. https://doi.org/10.20944/preprints202007.0549.v1

Barbarossa L. (2020). The Post Pandemic City: Challenges and Opportunities for a Non-Motorized Urban Environment. An Overview of Italian Cases. Sustainability, 12(17), 7172. https://doi.org/10.3390/su12177172

Batty, M. (2020). The Coronavirus crisis: What will the post-pandemic city look like? Environment and Planning B: Urban Analytics and City Science, 47(4), 547-552. https://doi.org/10.1177/2399808320926912

Blue -Nile. (2020). The Psychotically Effect of COVID-19. (Mohamed Osman, Interviewer). Retrieved from https://youtu.be/g4gZ3u2oN0c

Bravo, L., \& Tieben, H. editors. (2020). A yeas without public space under the Covid-19 pandemic, initiative by City Space Architecture and The Chinese University of Hong Kong, School of Architecture. Retrieved from https://www.journalpublicspace.org/index.php/jps/navigationMenu/view/covid-19

Broudehoux, Anne-Marie. (2021). Post-pandemic cities can permanently reclaim public spaces as gathering places as gatheringplaces. $\quad$ Retrieved from https://theconversation.com/post-pandemic-cities-can-permanently-reclaim-public-spaces-as-gathering-plac es-150729 
Clouston, S. A. (2021). Outdoor transmission of COVID-19: Analysis of windspeed. medRxiv preprint. https://doi.org/10.1101/2021.02.05.21251179

Corvacho, Helena. (2020). Thermal comfort in public space and sustainability. 3rd International Exergy, Life Cycle Assessment, and Sustainability Workshop. NISYROS - GREECE: University of Porto. Retrieved from https://www.researchgate.net/publication/337911379

D'Ascanio, R., \& Mondelli, F P. editors. (2021). KMO - Displaying Perceptions of Quarantine Landscape, online UNISCAPE Landscape Atelier - Cultivating Innovative Visions. Retrieved from https://www.uniscape.eu/km0-displaying-perceptions-of-quarantine-landscape $\% \mathrm{e} 2 \% 80 \% \mathrm{a} 8 /$

Echegaray, F. (2020). Anticipating the post-covid-19 world: implications for sustainable lifestyles. https://doi.org/10.2139/ssrn.3637035

ENVI-MET. (2021). ENVI-MET Software Program. Retrieved from https://www.envi-met.com

Freeman, Sh. (2020). COVID-19 and outdoor safety: Considerations for use of outdoor recreational. Canada: National Collaborating Centre for Environmental Health. Retrieved from https://ncceh.ca/documents/guide/covid-19-and-outdoor-safety-considerations-use-outdoor-recreational-spa ces

Geng, D., Innes, J., \& Wu, W et al. (2021). Impacts of COVID-19 pandemic on urban park visitation: a global analysis. J. For. Res., 32, 553-567. https://doi.org/10.1007/s11676-020-01249-w

Gruenwald, H. (2021). Covid-19 and Information Technology. USA: Researchgate.

Hamidi, S., Sabouri, S., \& Ewing, R. (2020). Does Density Aggravate the Covid-19 Pandemic? Journal of the American Planning Association, 86(4), 495-509. https://doi.org/10.1080/01944363.2020.1777891

Health, M. (2021). Mosque Protocoles. Retrieved from https://covid19awareness.sa/en/archives/10242

Honey, J. (2021). Public Spaces and Health in Post-Pandemic Cities. Retrieved from https://www.isglobal.org/en/healthisglobal/-/custom-blog-portlet/los-espacios-publicos-y-la-salud-en-la-ciu dad-pospandemia/8000927/12302

Jaing, S. (2021). Teachers' Voices on the Impact of COVID-19 on School Education: Are EdTech Companies Really the Panacea? Contemporary Education Dialogue, 18(1), 58-89. https://doi.org/10.1177/0973184920976433

Jalal, O. M. (2020). Impact of Evolving Building Morphology on Thermal Comfort in Public Spaces in Hot Arid Climate. Riyadh City, Kingdom of Saudi Arabia. Retrieved from https://amakenplacemaking.org/2020/07/25/coffee8-thermal-comfort-in-public-spaces-by-omar-galal/

Qian, M., \& Jiang, J. (2020). COVID-19, and social distancing. Journal of Public Health. https://doi.org/10.1007/s10389-020-01321-z

Khogali, H. (2020). The Effect of COVID-19 Corona Virus on Sustainable Teaching and Learning in Architecture Engineering. Modern Applied Science, 14(8). https://doi.org/10.5539/mas.v14n8p44

Kukenkov, V. (2020). Ergonomics and organization of interior space. Ergodesign, 38-41.

Lachlan, L. (2020). ADVANCING QUALITY TEACHING FOR ALL SCHOOLS Examining the Impact of COVID-19 on the Teaching Workforce. USA: The American Institute for Research.

de Lannoy, L., Rhodes, R. E., \& Moore, S. A. et al. (2020). Regional differences in access to the outdoors and outdoor play of Canadian children and youth during the COVID-19 outbreak. Canadian journal of public health, 111(6), 988-994. https://doi.org/10.17269/s41997-020-00412-4

Mark, Th. (2021). The Kingdom's Response to the COVID-19 Outbreak: Steps That Have Been Taken to Date, King Faisal Center for Research, and Islamic Studies. Saudi Arabia. Retrieved from https://kfcris.com/en/view/17

Mark, Themson. (2021). The Effect of CORONA on Teaching and Students in Saudi Arabia, King Faisal Center fore Research and Islamic Studies. Saudi Arabia. Retrieved from https://kfcris.com/en/view/17

Minor, M. $\quad$ T. (2018). Community. Retrieved from https://thriveglobal.com/stories/definition-of-social-life-what-it-is-meaning-and-concept/

NEERAJ MISHRA. (2020). Occupational Therapy Intervention in COVID 19. India: Occupational Therapy and COVID19 pandemic information $\&$ resources. 
News, A. (2021). Shopping Mall. Retrieved from https://www.arabnews.com/node/1666996/saudi-arabia

Park, Weather. (2021). Average Weather in Riyadh. Retrivied from https://weatherspark.com/y/104018/Average-Weather-in-Riyadh-Saudi-Arabia-Year-Round

Prevention, C. O. (2020). Coronavirus Disease 2019 (COVID-19). Retrieved from https://www.cdc.gov/coronavirus/2019-ncov/symptoms-

Sameh, S. (2020). Creating Resilient Cities-Jeddah Post COVID-19. Jeddah, Kindom of Saudi Arabia, Saudi Arabia. Retrieved from https://youtube.comlclArchiNet

Sameh, S. (2020). The Influence of COVID-19, and QUARANTINE on our Lifestyle, and Home Design. Jedda, Kingdom of Saudi Arabia, Saudi Arabia. Retrieved from https://youtube.comlclArchiNet

Scott, J. (May 2020). What risks does COVID-19 pose to society in the long-term? Zurich: Zurich Insurance Group.

Retrieved

from https:/www.weforum.org/agenda/2020/05/what-risks-does-covid-19-pose-to-society-in-the-long-term/

Solution, E. D. (2020). Post COVID-19 Design Solutions. New Delhi: Environmental Design Solution Limited. Retrieved

from https:/economictimes.indiatimes.com/company/environmental-design-solutions-private-limited/U74200DL 2009PTC189602

Sultan, F. A. (2021). Health and Local Comunity Response to COVID-19 in Saudi Arabia. Journal of Health and Allied science.

$\begin{array}{llll}\text { Tawakkalna. } & \text { (2021). } & \text { Tawakkalna } & \text { Software. }\end{array}$ https://play.google.com/store/apps/details?id=sa.gov.nic.tawakkalna\&hl=ar\&gl=US

Webster, M. (2020). Social Life. Retrieved from https://www.merriam-webster.com/dictionary/social\%20life

WHO. (2020). COVID-19 Small Public Gethering. Retrieved from https:/www.who.int/emergencies/diseases/novel-coronavirus-2019/question-and-answers-hub/q-a-detail/qa-small-public-gatherings-and-covid-19

Xie, J., Luo, S., Furuya, K., \& Sun, D. (2020). Urban Parks as Green Buffers During the COVID-19 Pandemic. Sustainability, 12(17), 6751. https://doi.org/10.3390/su12176751

\section{Copyrights}

Copyright for this article is retained by the author(s), with first publication rights granted to the journal.

This is an open-access article distributed under the terms and conditions of the Creative Commons Attribution license (http://creativecommons.org/licenses/by/4.0/). 